\title{
Mapping pre-harvest sprouting resistance loci in AAC Innova $\times$ AAC Tenacious spring wheat population
}

\author{
Raman Dhariwal' ${ }^{1}$, Colin W. Hiebert ${ }^{2}$, Mark E. Sorrells ${ }^{3}$, Dean Spaner ${ }^{4}$, Robert J. Graf ${ }^{1}$, Jaswinder Singh ${ }^{5}$ and
} Harpinder S. Randhawa ${ }^{* *}$

\begin{abstract}
Background: Pre-harvest sprouting (PHS) is a major problem for wheat production due to its direct detrimental effects on wheat yield, end-use quality and seed viability. Annually, PHS is estimated to cause $>1.0$ billion USD in losses worldwide. Therefore, identifying PHS resistance quantitative trait loci (QTLs) is crucial to aid molecular breeding efforts to minimize losses. Thus, a doubled haploid mapping population derived from a cross between white-grained PHS susceptible CV AAC Innova and red-grained resistant CV AAC Tenacious was screened for PHS resistance in four environments and utilized for QTL mapping.
\end{abstract}

Results: Twenty-one PHS resistance QTLs, including seven major loci (on chromosomes 1A, 2B, 3A, 3B, 3D, and 7D), each explaining $\geq 10 \%$ phenotypic variation for PHS resistance, were identified. In every environment, at least one major QTL was identified. PHS resistance at most of these loci was contributed by AAC Tenacious except at two loci on chromosomes 3D and 7D where it was contributed by AAC Innova. Thirteen of the total twenty-one identified loci were located to chromosome positions where at least one QTL have been previously identified in other wheat genotype(s). The remaining eight QTLs are new which have been identified for the first time in this study. Pedigree analysis traced several known donors of PHS resistance in AAC Tenacious genealogy. Comparative analyses of the genetic intervals of identified QTLs with that of already identified and cloned PHS resistance gene intervals using IWGSC RefSeq v2.0 identified MFT-A1b (in QTL interval QPhs.Irdc-3A.1) and AGO802A (in QTL interval QPhs.Irdc-3A.2) on chromosome 3A, MFT-3B-1 (in QTL interval QPhs.Irdc-3B.1) on chromosome 3B, and AGO802D, HUB1, TaVp1-D1 (in QTL interval QPhs.Irdc-3D.1) and TaMyb10-D1 (in QTL interval QPhs.Irdc-3D.2) on chromosome 3D. These candidate genes are involved in embryo- and seed coat-imposed dormancy as well as in epigenetic control of dormancy.

Conclusions: Our results revealed the complex PHS resistance genetics of AAC Tenacious and AAC Innova. AAC Tenacious possesses a great reservoir of important PHS resistance QTLs/genes supposed to be derived from different resources. The tracing of pedigrees of AAC Tenacious and other sources complements the validation of QTL analysis results. Finally, comparing our results with previous PHS studies in wheat, we have confirmed the position of several major PHS resistance QTLs and candidate genes.

Keywords: Seed dormancy, Seed coat color, Phytohormones, Genetic and epigenetic factors, Epistasis interactions

*Correspondence: harpinder.randhawa@agr.gc.ca

${ }^{1}$ Lethbridge Research and Development Centre, Agriculture and AgriFood Canada, 5403 1st Avenue South, Lethbridge, AB T1J 4B1, Canada Full list of author information is available at the end of the article

\section{Background}

Pre-harvest sprouting (PHS) or germination of mature grains on wheat heads before harvest, often caused by cool, wet conditions during the harvest season, may tion and reproduction in any medium or format, as long as you give appropriate credit to the original author(s) and the source, provide a link to the Creative Commons licence, and indicate if changes were made. The images or other third party material in this article are included in the article's Creative Commons licence, unless indicated otherwise in a credit line to the material. If material is not included in the article's Creative Commons licence and your intended use is not permitted by statutory regulation or exceeds the permitted use, you will need to obtain permission directly from the copyright holder. To view a copy of this licence, visit http://creativecommons.org/licen ses/by/4.0/. The Creative Commons Public Domain Dedication waiver (http://creativecommons.org/publicdomain/zero/1.0/) applies to the data made available in this article, unless otherwise stated in a credit line to the data. 
result in significant losses in wheat yield, end-use quality (test weight, milling and baking properties), seed viability and seedling vigor [1-6]. PHS is a global problem which occurs in many countries of the world including Australia, Canada, China, Germany, India, Japan and USA [7, 8]. In Canada, PHS causes significant damage to wheat production in the eastern and northern Prairies. PHS is estimated to cost the wheat industry average losses of US $\$ 100$ million in Canada and $>\$ 1$ billion worldwide annually in the years favorable for PHS [9-12].

Continuous wet conditions at ripening triggers a sequence of physiological processes in the seed, which includes the release of hydrolytic enzymes such as $\alpha$-amylases, lipases, and proteases [1, 13]. Reduced grain test-weight and low falling number are observed in PHS affected samples due to the conversion of starch to glucose by $\alpha$-amylases [14, 15]. Increased activity of amylases, lipases and proteases affect bread and noodle making quality $[1,15,16]$. Losses in functional baking quality due to PHS may include low flour absorption, reduced dough strength and loaf volume, and poor crumb structure [17, 18]. Additionally, PHS can affect baking properties by making the dough porous, sticky and off-color [1].

PHS is influenced by several environmental and genetic factors $[2,4,6]$ and is associated with several developmental, physiological, and morphological features of the seed and spike (reviewed in [1]). These includes seed coat (pericarp) color and permeability, $\alpha$-amylase activity, level of plant growth hormones (abscisic acid, ABA; gibberellin, GA; auxin), and seed dormancy (reviewed in [1]). The presence of awns, spike shape, openness of florets, glume rigidity and germination inhibitors in the husk and bracts $[13,19,20]$, along with glume epicuticular wax, glume adherence and head inclination, etc. [21] also affect PHS resistance [6]. Among all these characteristics, seed dormancy [1, 5-7] and spike morphology [6] are the most important genetic factors influencing PHS resistance [6].

Seed dormancy is believed to be the predominant control of PHS resistance [7] and has received much attention in breeding programs [1]. Seed dormancy prevents germination at early stages after physiological maturity and it dissipates over time so that germination occurs in more favorable conditions to enable the survival of plants in hostile environments [7]. Seed dormancy is primarily seed coat- and embryo-imposed [6, 22].

The seed coat provides dormancy by acting as a physical barrier to imbibition and radicle growth [7] but additionally may stop germination by seed coat inhibitors $[6,23,24]$. Seed coat imposed dormancy mechanisms correlate positively with seed coat color due to phenolic compounds in diverse species [1]. The red grain color due to catechin and proanthocyanidin flavanol pigments $[25,26]$ in the testa (seed coat) of wheat is also associated with seed dormancy $[1,22,27] . R$ genes genetically control testa color in wheat and are mapped to the distal region of homeologous group 3 chromosomes [28]. $R$ genes act as transcriptional activators of the flavonoid synthesis pathway genes chalcone synthase $(\mathrm{CHS})$, chalcone isomerase $(C H I)$, flavanone 3-hydroxylase $(F 3 H)$, and dihydroflavonol 4-reductase (DFR) [29]. Myb-type transcription factor genes (Tamyb10-A1, Tamyb10-B1 and Tamyb10-D1), which are located to the same genetic intervals as the $R$ loci, control the red grain color of wheat by up-regulating the flavonoid biosynthesis pathway structural genes DFR, CHI, F3H, and CHS [1,29].

Embryo-imposed dormancy is precisely regulated by seed developmental processes [7]. ABA and its crosstalk with GA and auxin play fundamental roles in regulating embryo-imposed dormancy [1, 7]. A number of genes involved in ABA biosynthesis and signal transduction have been identified to have roles in seed dormancy in diverse species [30]. The Viviparous-1 (Vp-1)/Abscisic Acid Insensitive3 (ABI3) gene, which encodes a dormancy related-transcription factor and is involved in ABA signal transduction, is an important regulator of late embryogenesis in maize and late embryo development in wheat [31-33]. The TaVp-1 loci are located approximately $30 \mathrm{cM}$ proximal to the $R$ genes on the group 3 chromosomes of wheat $[29,34,35]$. A number of other ABA synthesis and signal transduction pathway genes such as wheat homolog of Mother of FT and TFL1 (TaMFTlike/TaPHS1), ABA-induced Wheat Plasma Membrane 19 (PM19-A1/A2) [36], wheat homolog of cytochrome P450 family 707 subfamily $A$ polypeptide 1 gene (TaCYP707A1) and Delay of Germination 1 (TaDOG1) have been found associated with seed dormancy [2, 37-42].

Several studies demonstrated that epigenetic modifications through DNA [43] and histone methylation [44, 45] can also influence seed dormancy and PHS resistance [5]. Histone deacetylases have also been found to modulate seed germination and ABA-induced gene expression in Arabidopsis $[46,47]$ and have been found to be modulated by ABA in barley [48]. Recently, the role of $A R G O$ NAUTE genes of ARG4_9 class, which play key roles in DNA silencing in plants through the RNA dependant DNA methylation (RdDM) pathway, was explored in wheat and barley $[5,43]$. An association of DNA methylation and polymorphism in ARGONAUTE gene $A G O 802 B$ on chromosome $3 \mathrm{~B}$ and PHS resistance was demonstrated in embryos of PHS resistant and susceptible cultivars of wheat [5].

All wheat chromosomes possess quantitative trait loci (QTLs) associated with PHS resistance, resulting in a 
total 110 loci in wheat [6]. QTLs have been repeatedly reported on groups 3 and 4 chromosomes from different wheat genotypes [6], such as the major QTLs QPhs. pseru-3A/TaPHS1 on chromosome arm 3AS [42, 49, 50] and Phs1 on chromosome arm 4AL [51, 52]. In addition to genes/QTLs mentioned above, causal/candidate genes from some of the PHS associated QTLs have also been cloned/identified such as mitogen-activated protein kinase kinase 3 (TaMKK3-A) for Phs1 QTL on chromosome arm 4AL [52], TaSdr-A1a [53], and TaSdr-B1 [7].

In wheat, red-grained cultivars are generally more PHS resistant than those that are white-grained [34]. Using genealogical analysis of 148 red-grained and 63 whitegrained North-American spring wheat cultivars with varying level of PHS resistance, Martynov and Dobrotvorskaya [54] found that cultivars with different genetic backgrounds may have different sources of resistance. The genetic resistance in red-grained cultivars came from source genotype groups (i) Crimean, Hard Red Calcutta and Iumillo, (ii) Button, Kenya 9M-1A-3 and Kenya-U, and (iii) Red Egyptian and Kenya BF4-3B-10V1, respectively, via donor cultivars (i) Thatcher, (ii) Kenya-Farmer, and (iii) Kenya-58 [54]. The genetic resistance in whitegrained cultivars came from genotypes Akakomugi, Crimean, Hard Red Calcutta, Hybrid English, Iumillo, Ostka Galicyjska, Rough Chaff, White Red King and Turco via donor cultivars Frontana, RL2265 and Thatcher [54]. RL4137 is another important PHS-resistant line of Canadian origin and has been included in the parentage of vast majority of PHS resistant North-American red- and white-grained spring wheat accessions [54, 55]. In addition to the above mentioned North American sources, a number of other red- and white-grained genotypes have been reported to possess PHS resistance across the globe. Some of these include Chinese landraces RSP and Chinese Spring [56, 57], French cv Renan [34], Indian breeding line SPR8198 and cv HD2329 [58], Japanese breeding line OS21-5 and cv Zenkoujikomugi [2, 51, 57, 59, 60], and Mexican cv Opata [61].

Domestication and the desire of breeders to develop cultivars using reduced time frames as required in contra-season nurseries and speed breeding, continued selection for uniform and rapid germination and seedling establishment in wheat cultivars has worked against seed dormancy and made modern cultivars susceptible to PHS [38, 62-67]. Therefore, breeding programs have to meet contradictory demands of high level of seed dormancy during harvest time and high level of germination after seeding [2]. To satisfy these demands, different mechanisms controlling PHS resistance and subsequent germination after seeding must be identified [2].

AAC Tenacious is a modern Canadian red-grained, highly PHS resistant spring wheat cultivar [68] which has several North American PHS-resistant sources, such as RL4137, in its parentage. However, the PHS resistance of AAC Tenacious is not yet completely understood. The objectives of the present study were to identify QTLs for PHS resistance in AAC Tenacious using a large doubled haploid (DH) population, compare identified QTLs with the previously reported QTLs, and identify candidate genes using comparative analyses.

\section{Results}

\section{PHS resistance evaluation}

Strong phenotypic variability for sprouting was observed between the parents (Fig. 1), check cultivars (Additional file 1: Fig. S1) and DH lines across environments, except Edmonton 2019 (Figs. 1 and 2, and Additional file 2: Table S1) but the differences were significant in all the environments. In Edmonton 2019, weather conditions at harvest were relatively cold, which delayed physiological maturity. ANOVA also showed significant environment and genotype effects for PHS (Additional file 2: Table S2). The estimated broad-sense heritability of the PHS trait was 0.71 .

Parent cultivars showed different PHS phenotypes across environments. The average PHS score for the resistant parent, AAC Tenacious, ranged from 1.0 in Edmonton 2019 and Ithaca 2018 environments to 1.4 in Lethbridge 2019. The average score for the PHS susceptible parent, AAC Innova, ranged from 1.8 in Edmonton 2019 to 8.7 in Lethbridge 2019 (Additional file 2: Table S1). Mean PHS data showed that AAC Tenacious and AAC Penhold were the most resistant cultivars while $\mathrm{AAC}$ Brandon, AAC Awesome and AC Andrew were the

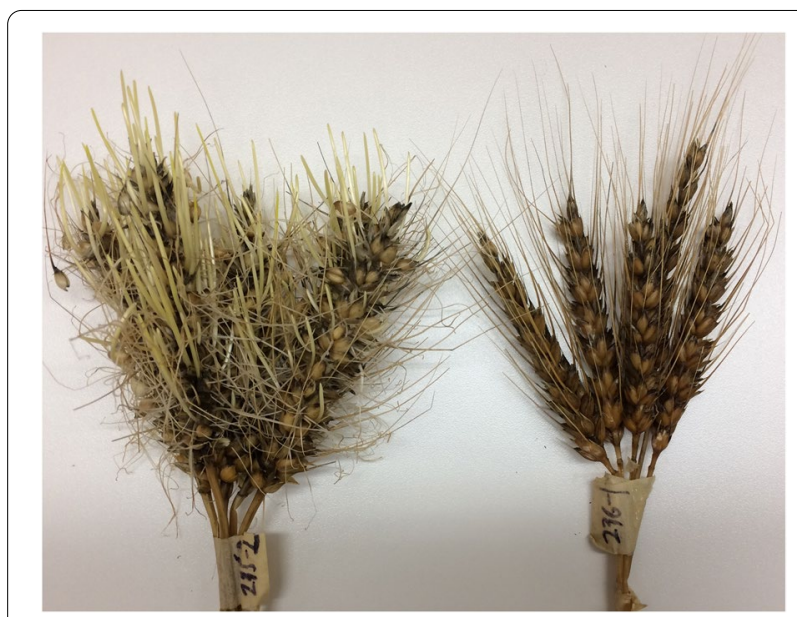

Fig. 1 Pre-harvest sprouting (PHS) phenotypes of population parents after 4 days in a mist chamber. PHS-susceptible cultivar AAC Innova is shown on left-hand side while PHS-resistant cultivar AAC Tenacious is shown on right-hand side 


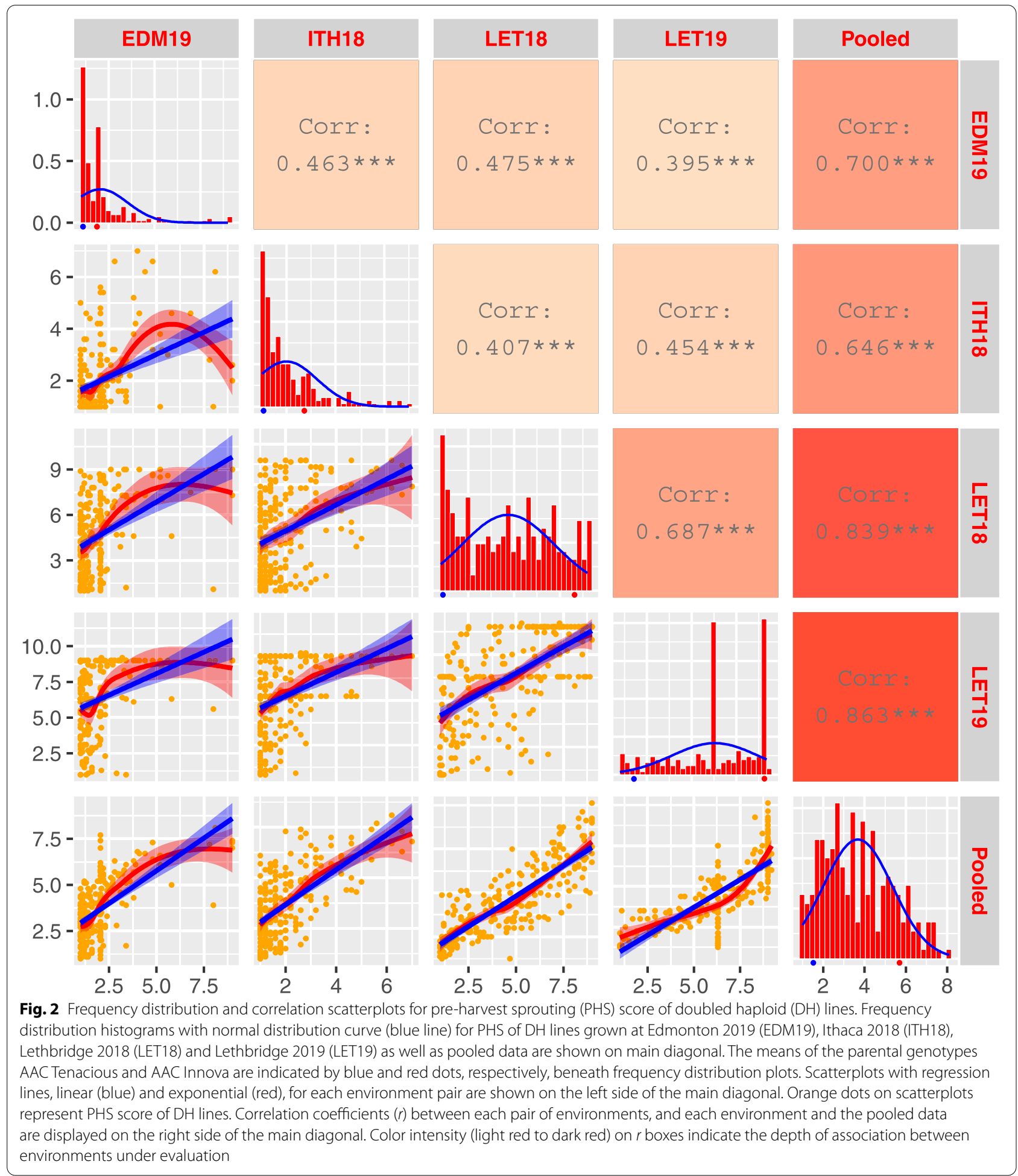

most susceptible cvs among the parent and check cultivars (Additional file 2: Table S1).

The DH population also differed broadly for PHS, with the resistant and susceptible DHs deviating by the rating score of 7.5 where the mean of population was 3.7 (Additional file 2: Table S1). Population PHS means were within the range of the two parents across environments (Additional file 2: Table S1). However, among the parents, 
the lowest PHS was seen in Edmonton 2019 (mean 1.4, ranged from 1.0 to 1.8 ) and the highest PHS was seen in Lethbridge 2019 (mean 5.05, ranged from 1.4 to 8.7) (Additional file 2: Table S1). Moreover, Edmonton 2019 and Ithaca 2018 environments were phenotypically similar, as were Lethbridge 2018 and 2019 (Additional file 2: Table S1). Conversely, Lethbridge 2019 had the highest PHS mean scores while Edmonton 2019, Ithaca 2018 and Lethbridge 2018 had the first, second and third lowest means, respectively (Additional file 2: Table S1).

Frequency distribution plots showed a skewed distribution (towards resistance) of sprouting phenotypes in the population across environments except in Lethbridge 2019 (Fig. 3). However, a broader range of genotypes was observed across environments. In Lethbridge 2019, a number of DHs which previously showed less sprouting, revealed relatively high sprouting, perhaps due to some epigenetic changes.

Correlation coefficients $(r)$ for the PHS scores between any pair of environments were moderate to high (ranged from $0.40-0.69)$ with a moderate $(0.48)$ mean correlation coefficient (Fig. 2). No strong trend was observed in correlations between locations within a single year or 2 years, though the highest correlation (0.69) was observed at the Lethbridge location between 2018 and 2019 (Fig. 2). Heritability across the four trial environments was 0.71 . Since the correlation between environments was generally lower than broad-sense heritability, these results suggest the existence of a strong environmental influence on genotypes [69].

\section{Quantitative trait loci for PHS resistance Main-effect QTLS}

Composite interval mapping (CIM) analysis was carried out individually for each environment using PHS data of individual environments as well as the pooled (average of all environments) data to identify main effect QTLs for PHS resistance. CIM detected a total of 20 different PHS resistance QTLs on wheat chromosomes $1 \mathrm{~A}, 2 \mathrm{~A}, 2 \mathrm{~B}, 2 \mathrm{D}$, 3A, 3B, 3D, 4A, 4B, 4D, 5A, 7A and 7D (Fig. 3, Table 1 and Additional file 2: Table S3). Conversely, mixed-model based composite interval mapping (MCIM) identified a total of eleven QTLs (Additional file 2: Table S4). These included ten loci which were also detected using CIM and an additional minor QTL, QPhs.lrdc-2B.2, on chromosome 2B (Additional file 2: Table S4).

Phenotypic variation $\left(R^{2}\right)$ explained by twenty maineffect loci detected using CIM ranged from 4.0\% (QPhs. lrdc-3B.1, QPhs.lrdc-4D, QPhs.lrdc-5A.1 and QPhs.lrdc$7 A$ ) to $19.0 \%$ (QPhs.lrdc-3A.1) (Fig. 3 and Table 1). The LOD score of individual QTLs ranged from 2.50 (QPhs. $l r d c-5 A .2)$ to 12.00 (QPhs.lrdc-3A.1) and the additive effect (AE) ranged from 0.32 (QPhs.lrdc-1A.1) to 1.43
(QPhs.lrdc-2B.1) (Fig. 3 and Table 1). Only seven of the total identified loci (located on chromosomes 1A, 2B, $3 \mathrm{~A}, 3 \mathrm{~B}, 3 \mathrm{D}$, and 7D; Table 1) explained $\geq 10 \% R^{2}$ for PHS (Fig. 3 and Table 1) and were considered major QTLs. However, based on the LOD score $(\geq 5.0)$, the AE $(\geq 1.0)$ and the $R^{2}(\geq 10.0)$ values, three QTLs (QPhs.lrdc-2B.1, QPhs.lrdc-3A.1 and QPhs.lrdc-7D) were narrowed down to be highly effective and major QTLs.

Notably, where in each individual environment there was at least one major QTL detected (Fig. 3 and Table 1), together four QTLs (QPhs.lrdc-2B.2, QPhs.lrdc-3A.1, QPhs.lrdc-4A and QPhs.lrdc-7A) were identified in at least three environments as well as in the pooled data (Fig. 3 and Table 1). While PHS resistance alleles at around three quarters of the total detected loci were contributed by AAC Tenacious, AAC Innova, the susceptible parent, also contributed resistance alleles at six QTLs, which included two major loci, QPhs.lrdc-3D.1 and QPhs. lrdc-7D (Fig. 3 and Table 1).

\section{Digenic epistasis interaction}

Two of the above mentioned main effect QTLs on chromosomes 1A (QPhs.lrdc-1A.1) and 7A (QPhs.lrdc-7A) were found to be involved in digenic epistasis interaction (Fig. 3, Table 1 and Additional file 2: Tables S4 and S5). Notably, although these QTLs did not contribute much $\left(R^{2}: 4\right.$ to $5 \%$ and AE: 0.32 to 0.49$)$ individually, their epistatic interaction indicates that the parental two-locus genotypes had additional negative effect on sprouting (AA value: -0.24 , phenotypic variance: 4.9 ) (Additional file 2: Table S5).

\section{Combined effect of major PHS resistance QTLs on sprouting}

Pooled PHS and single nucleotide polymorphism (SNP) genotyping data of all the DH lines were analyzed for the linked markers $\left(K u \_c 44068 \_601, T d u-\right.$ rum_contig1653_190, Tdurum_contig83209_316, BS00057988_51, wsnp_Ex_c7780_13254349, BS00067163_51, and D_GCE8AKX02ILA1U_88) for all major QTLs (QPhs.lrdc-1A.2, QPhs.lrdc-2B.1, QPhs. lrdc-3A.1, QPhs.lrdc-3B.2, QPhs.lrdc-3D.1, QPhs.lrdc$3 D .2$ and QPhs.lrdc-7D) detected in this study. PHS data of DH lines having the same genotypic profile for each group of markers were pooled, and mean PHS and standard deviation were estimated. Mean PHS of each group of DH lines, or unique line with a single QTL and combination of QTLs, were plotted as bar plots and line graph (Additional file 3: Fig. S2). DHs across environments showed a gradual increase in PHS resistance with increasing number of QTLs (Additional file 3: Fig. S2). Notably, a highly resistant phenotype was observed only when at least five major QTLs were present together (Additional file 3: Fig. S2). Conversely, some lines were 


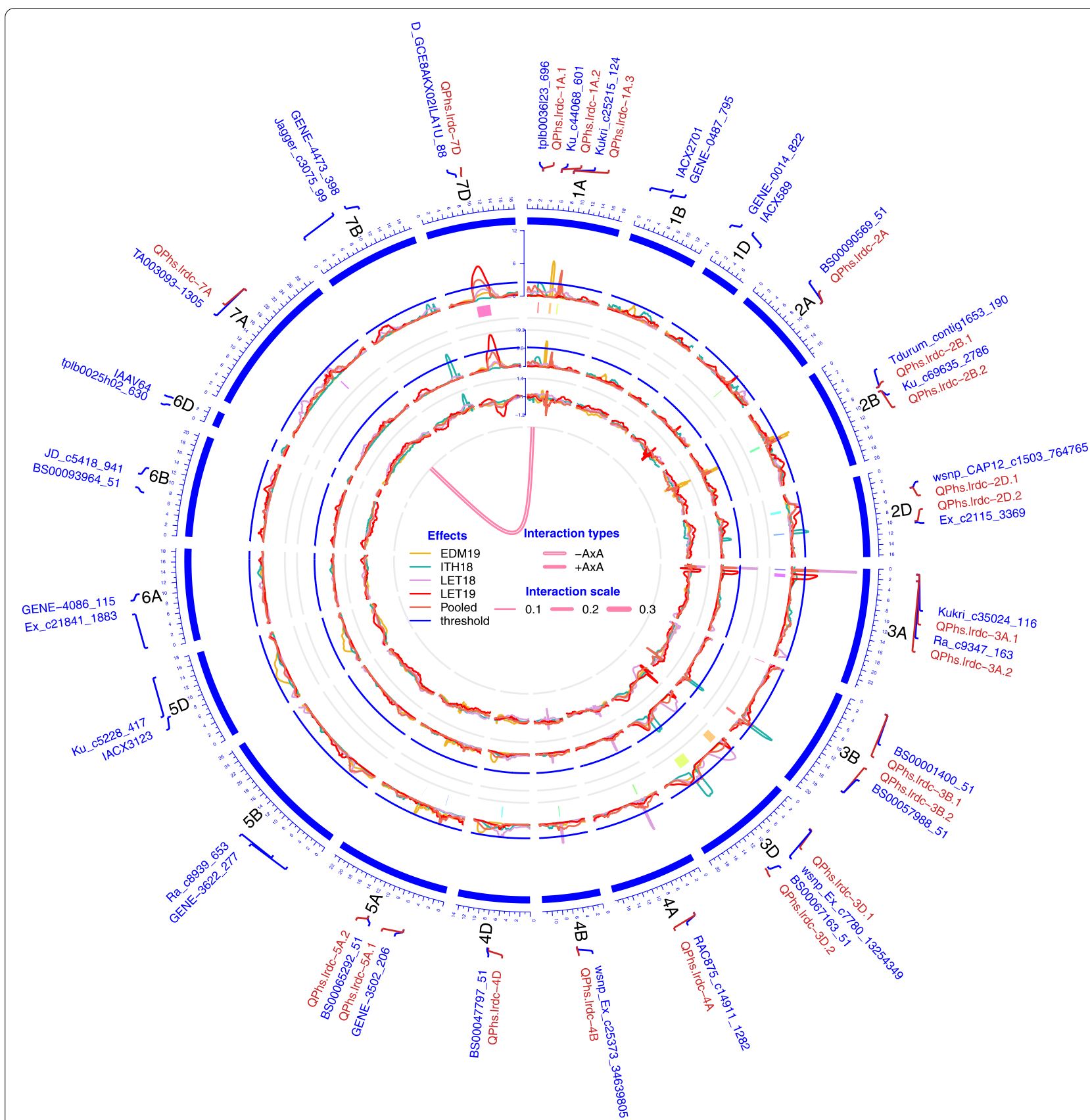

Fig. 3 Circos diagram. Complete results of quantitative trait loci (QTL) and epistasis interaction identified for pre-harvest sprouting (PHS) resistance from AAC Innova/AAC Tenacious doubled haploid mapping population using composite interval mapping are shown in Circos diagram. The outermost track shows the 21 chromosomes (1A-7D) arranged in clockwise direction with PHS resistance QTLs (in red color font) and their linked or few randomly selected markers (in blue color font) in $0.1 \mathrm{X}$ scale (CM). Three inner tracks and line connections in the middle, respectively, represent the mean LOD score (second track from outside), \% phenotypic variation $\left(R^{2}\right)$ explained (third track from outside), additive effect (AE) (fourth track from outside) of individual QTLs and epistatic effect (AA) of digenic QTL $\times$ QTL interactions (line connection in the middle) for PHS resistance in different environments. In the second and third tracks from outside, blue lines show a LOD threshold of 2.5 and $R^{2}$ threshold of $10 \%$, respectively. QTL confidence intervals are shown in different colors beneath the QTL scans in second track from outside. LOD score, \% $R^{2}$ and AE peaks for different environments are represented by different colors as shown in the effects legend in the middle of the Circos diagram. A negative QTL $\times$ QTL interaction between QTLs QPhs.Irdc-1A.1 and QPhs.Irdc-7A, on chromosomes 1A and 7A, is shown as line connection in the middle of the Circos diagram. The width of the line connection represent the strength of AA effect, as shown in the AA interaction scale 


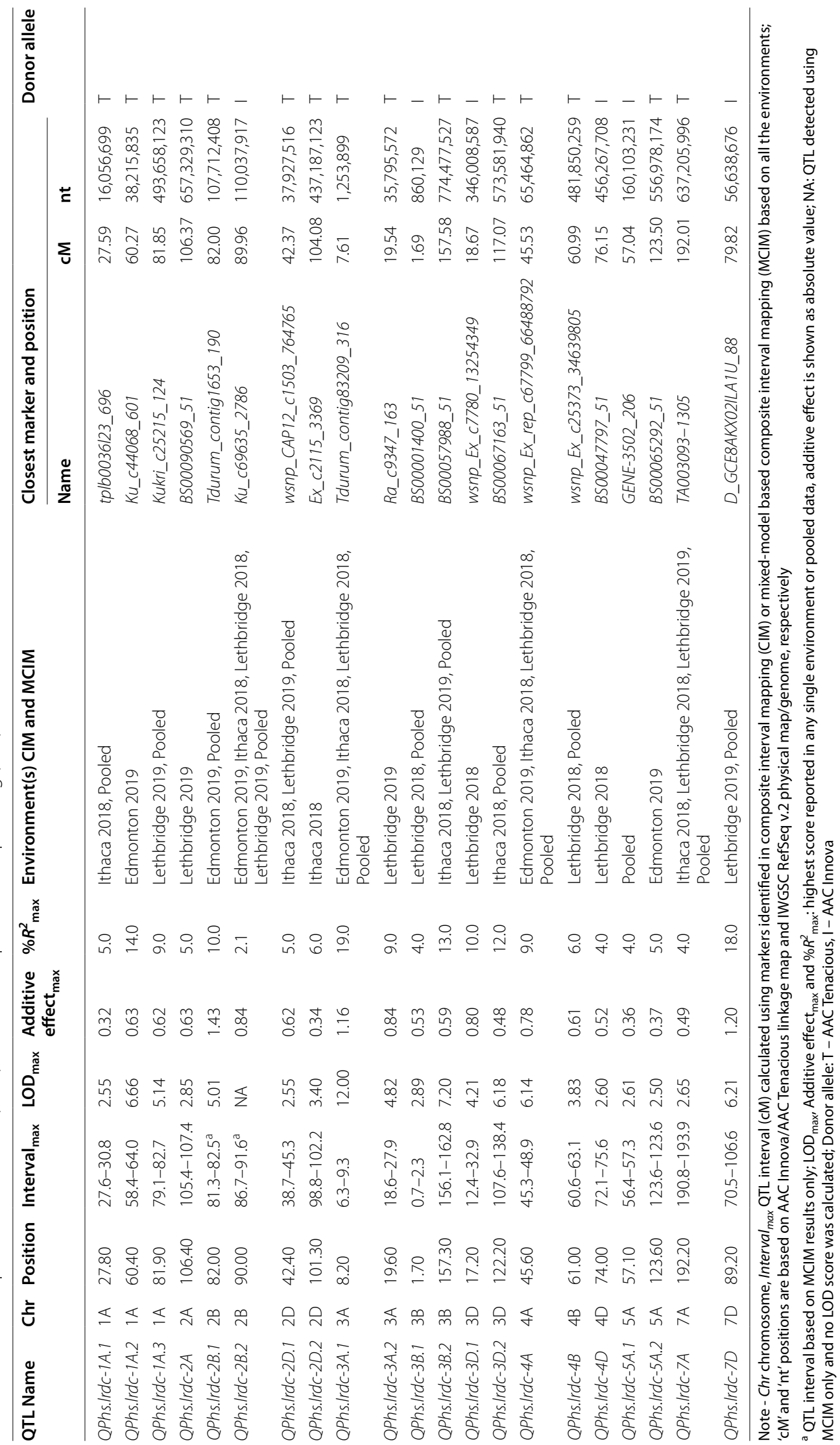


relatively more susceptible than other lines in their group even in the presence of resistance alleles at five QTLs, which indicates that other factors also influence PHS resistance.

To identify the most effective QTL and to assess the specific effect of QTLs, only three main major and effective QTLs, namely QPhs.lrdc-2B.1, QPhs.lrdc-3A.1 and QPhs.lrdc-7D, were selected. Based on the genotyping profile of these QTLs, the DH lines were categorized into eight different genotypic classes (Additional file 2: Table S6), irrespective of the PHS resistance alleles at other detected/undetected loci. Mean PHS of each group of DH lines for each individual QTL and group of QTLs was plotted as boxplots (Fig. 4). It was observed that while individually, QPhs.lrdc-3A.1 contributed maximum PHS resistance, a gradual decrease in sprouting was observed with increasing number of QTLs (Fig. 4) indicating the cumulative AE. However, statistically significant differences in mean PHS of the susceptible vs resistant groups were observed only when at least two QTLs were present, particularly QPhs.lrdc-3A.1 and one other QTL (Fig. 4).

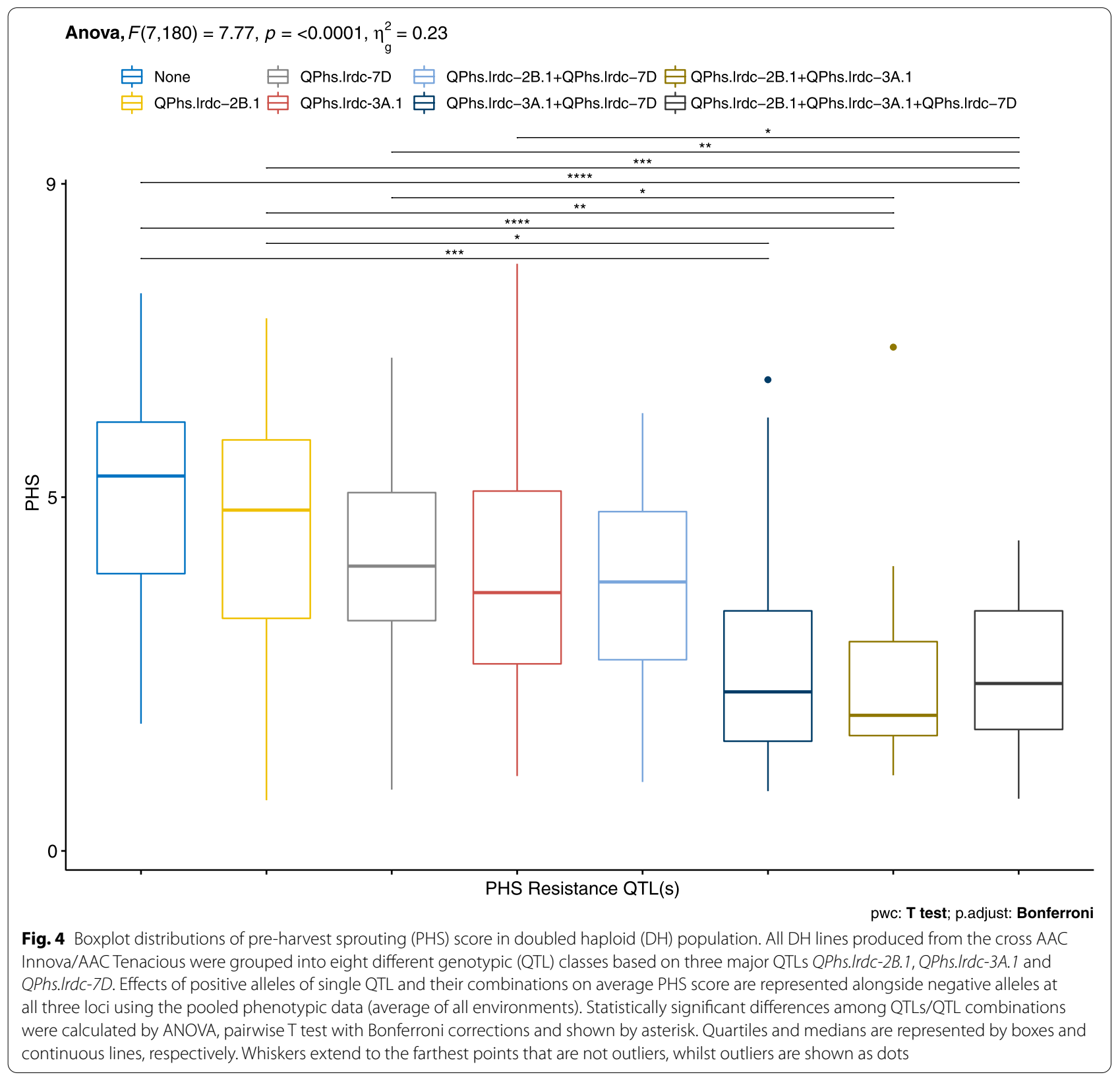




\section{QTL genome locations and comparisons with previously identified QTLs/genes}

Based on all the SNP markers mapped to the QTL regions in this study, physical positions of all the markers on the wheat reference genome (IWGSC RefSeq v2.0) were detected (Additional file 2: Tables S7, S8). This led to the identification of physical intervals of all the QTLs on wheat chromosomes (Table 2). Results from a total of 32 previously published studies and various numbers of other genes from different online sources (Additional file 2: Table S9) were assessed to check if they overlap physical intervals (on reference genome) of QTLs detected in this study. We found that 13 of the 21 main effect-loci identified in this study appeared to shared chromosome positions where at least one QTL has been previously identified in other wheat genotype(s) (Table 2). The remaining eight QTLs appear to be new and were identified for the first time in this study. These new QTLs also include two major QTLs, QPhs.lrdc-2B.1 and QPhs. lrdc-3B.2, and a most stable but minor QTL, QPhs.lrdc$2 B .2$, which was identified across environments and in the pooled data. AAC Tenacious contributed resistance at these two major QTLs, while AAC Innova at minor QTL QPhs.lrdc-2B.2 (Tables 1 and 2).

Comparative analyses of the genomic intervals of QTLs detected in this study with that of previously identified and cloned PHS resistance genes identified several candidate genes in QTL regions (Table 2). These include Ppd-D1b (in QTL interval QPhs.lrdc-2D.1), MFT-A1b (in QTL interval QPhs.lrdc-3A.1) and AGO802A (in QTL interval QPhs.lrdc-3A.2) on chromosome 3A, MFT-3B-1 (in QTL interval QPhs.lrdc-3B.1) on chromosome 3B, and $A G 0802 D$ and TaVp1-D1 (in QTL interval QPhs. lrdc-3D.1) and TaMyb10-D1 (in QTL interval QPhs.lrdc3D.2) on chromosome 3D (Table 2).

One of the above candidate genes, $P p d-D 1$, a photoresponse and domestication gene, was assessed for its association with PHS resistance and days to anthesis (DTA). Genetically, Ppd-D1 was mapped to QPhs.lrdc$2 D .1$ interval within $1.61 \mathrm{cM}$ of the closely linked SNP marker wsnp_CAP12_c1503_764765 (Table 1 and Additional file 2: Table S7). It was observed that the AAC Tenacious derived photoperiod-sensitive allele Ppd$D 1 b$ significantly reduced pre-harvest sprouting in AAC Innova/AAC Tenacious population, irrespective of other genes/QTLs (Fig. 5). On the other hand, DTA showed weak negative association $(r-0.20)$ with PHS resistance.

A detailed AAC Tenacious pedigree chart with information of different PHS-resistant sources was generated (Additional file 4: Fig. S3). Interestingly, AAC Tenacious has several PHS-resistant bread wheat landraces/genotypes [Akakomugi (landrace, Japan), Button (cultivar, Kenya), Crimean (landrace, USA), Frontana (cultivar, Brazil), Hard Red Calcutta (landrace, India), Kenya-Farmer (cultivar, Kenya), Kenya 9 M-1A-3 (breeding line, Kenya), Kenya-U (breeding line, Kenya), Ostka Galicyjska (landrace, Poland), RL2265 (breeding line, Canada), RL4137 (breeding line, Canada), Thatcher (cultivar, USA) and Turco (landrace, Brazil)] and a durum cultivar Iumillo (USA) in its parentage as progenitors (Additional file 4: Fig. S3). A number of pedigrees (Additional file 5) of the cultivars/genotypes including AAC Innova and that previously reported to possesses PHS resistance QTL(s)/gene(s) in the same chromosomal regions where QTLs have been reported in this study were also searched. It was observed that AAC Tenacious or AAC Innova shared their pedigrees with at least 9 (out of all the cultivars/genotypes with known pedigrees) different PHS-resistant cultivars/genotypes (AC Domain, Leader, Renan, HD2329, OS21-5, Opata, Cayuga, Danby and Rio Blanco) from six different countries (Canada, France, India, Japan, Mexico and the USA) (Table 2). AAC Tenacious and AAC Innova do not share their pedigrees with two resistant cultivars/genotypes, RSP (from China) and Zenkoujikomugi (from Japan) and susceptible landrace Chinese Spring (from China) (Table 2).

\section{Discussion}

PHS is a serious threat to wheat production in many growing areas, particularly where late seasonal rainfall occurs during harvest. In recent years, it has become more frequent due to uncertain weather conditions linked with climate change [53]. Integrating PHS resistance in modern wheat cultivars is a major breeding objective in many countries including Australia, Canada, China, Japan and USA [53]. Seed dormancy is considered the dominant factor in controlling PHS resistance in cereals [7]; however, highly dormant seed is considered to be a limiting factor in obtaining uniform germination and early seedling establishment [62]. Thus, to meet the contradictory demands of PHS resistance and proper germination when required, breeding programs need to incorporate alternate mechanisms into modern cultivars [2] such as moderate dormancy in combination with modified spike morphology.

AAC Tenacious is a highly PHS resistant, tall, photoperiod-sensitive and red-grained Canadian wheat cultivar [68]. It also possesses a gibberellic acid (GA)-sensitive tall plant height allele $R h t-B 1 a$ and the brassinosteroidsensitive tall plant height allele Rht8a [74] at Xgwm261 locus [75]. Above features make AAC Tenacious assessment important, not only for red-grain associated factors, but also for alternate physiological mechanisms including photoperiodic response. To this objective, AAC Tenacious was crossed with the white-grained, semi-dwarf, soft-textured and photoperiod-insensitive 


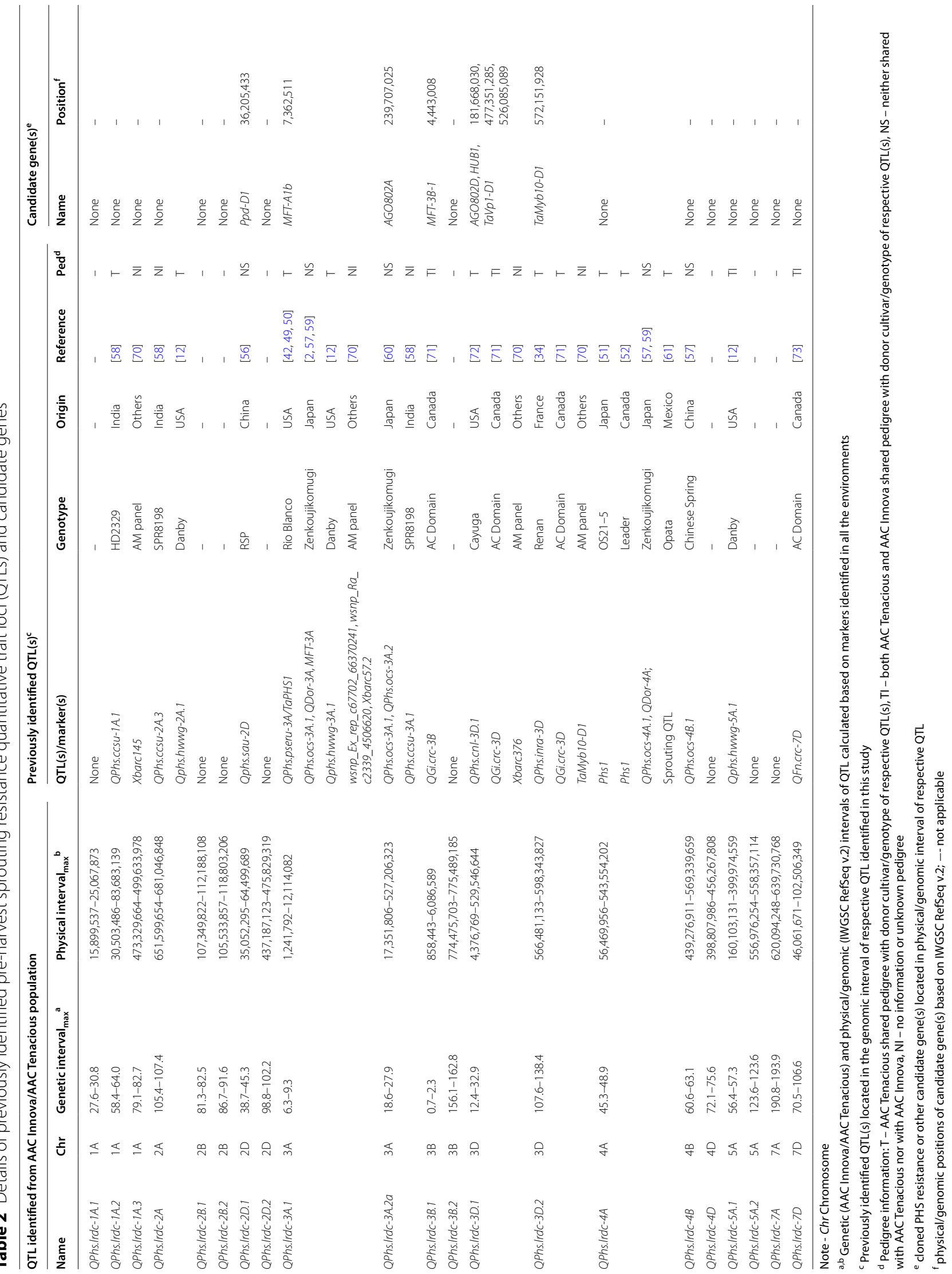


Canadian wheat cv AAC Innova [76] to develop a diverse DH mapping population.

Parents of this population showed contrasting PHS phenotypes and the DH population was skewed toward resistance in the three out of four environments (Fig. 2), suggesting the involvement of multiple large-effect genes/QTLs responsible for PHS resistance. As indicated by the phenotypic analysis, this population segregated for seven major QTLs along with 14 minor QTLs (Table 1). This can be explained by the parentage of AAC Tenacious which is composed of several PHS-resistant sources (Additional file 4: Fig. S3) such as Thatcher, Hard Red Calcutta, Ostka Galicyjska, RL4137, etc. [54]. Moreover, it is known that seed dormancy is controlled by multiple genes/QTLs distributed over all 21 wheat chromosomes [59]. The contributions of such multiple PHS resistance QTLs from a single cultivar have also been reported previously [58].

Together, 21 PHS resistance loci were identified in the present study including 15 from AAC Tenacious and six from AAC Innova (Table 1). These also included seven major QTLs, each individually explained $\geq 10 \%$ phenotypic variation (PV) (Table 1). Notably, most of the other QTLs, that explained $<10 \%$ PV, were detected in single environments and considered to be small effect [77] suggestive [78] QTLs. Major PHS resistance QTLs were QPhs.lrdc-1A.2, QPhs.lrdc-2B.1, QPhs.lrdc-3A.1, QPhs. lrdc-3B.2, QPhs.lrdc-3D.1, QPhs.lrdc-3D.2 and QPhs. lrdc-7D (Fig. 3 and Table 1). Broadly, only three QTLs (QPhs.lrdc-2B.1, QPhs.lrdc-3A.1 and QPhs.lrdc-7D) were considered highly effective QTLs based on the high LOD score, AE and the explained PV. Interestingly, AAC Tenacious contributed resistance alleles at all these three loci.

On the other hand, four QTLs (QPhs.lrdc-2B.2, QPhs. lrdc-3A.1, QPhs.lrdc-4A and QPhs.lrdc-7A) were detected in at least three environments as well as in the pooled data. These QTLs are considered the most stable QTLs identified in this study; however, QPhs.lrdc-3A.1 is the only major QTL (explained up to $19.0 \%$ PV) among the four loci. Remaining 17 loci were detected in either $\leq 2$ environments (with or without pooled data) or just in the pooled data. These results suggest a high environmental effect on expression of PHS resistance, which is expected for a quantitative trait [58] influenced by several environmental and genetic factors $[2,4,6]$.

Despite the number of QTLs identified previously from different genotypes (reviewed in [1]), 8 QTLs (QPhs.lrdc1A.1, QPhs.lrdc-2B.1, QPhs.lrdc-2B.2, QPhs.lrdc-2D.2, QPhs.lrdc-3B.2, QPhs.lrdc-4D, QPhs.lrdc-5A.2 and QPhs. lrdc-7A) identified in this study are reported for the first time (Table 2). These include a relatively stable major QTL QPhs.lrdc-3B.2 (detected in Ithaca 2018, Lethbridge 2019 and the pooled data) derived from AAC Tenacious and do not seem to be homoeo-QTL or paralogues. This reinforces the importance of AAC Tenacious in dissecting $\mathrm{PHS}$ resistance.

All the important QTLs are discussed first in greater details followed by others below. QPhs.lrdc-3A.1, a very important QTL, explained the most PV (up to 19.0\%) of PHS trait and had the highest LOD score of 12.0. The AAC Tenacious allele at this locus had $1.16 \mathrm{AE}$ which reduces sprouting by around $13.0 \%$. This QTL was detected in Edmonton 2019, Ithaca 2018, Lethbridge 2018 and the pooled data, and is considered one of the most stable QTL identified in this study. Interestingly, a number of QTLs, such as QPhs.pseru-3A/TaPHS1, QPhs.ocs-3A.1, QDor-3A, Qphs.hwwg-3A.1, from cultivars like Rio Blanco and Danby (USA) and Zenkoujikomugi (Japan) [2, 12, 42, 49, 50, 57, 59], and a number of markers, such as wsnp_Ex_rep_c67702_66370241, wsnp_Ra_c2339_4506620, and Xbarc57.2, from diverse winter wheat association mapping panels [70] have been mapped to the same overlapping region as QPhs.lrdc3A.1. Notably, AAC Tenacious shares its pedigree with US cvs Rio Blanco and Danby, but Japanese cv Zenkoujikomugi is unrelated to AAC Tenacious. Unexpectedly, the presence of this QTL in different cultivars with related/unrelated pedigrees showed the robustness and usefulness of this QTL for breeding PHS resistant wheat in different genetic backgrounds. A causal gene, MFTA1b/TaPHS1 (Mother of FT and TFL1), has also been cloned from this region previously [2]. Comparative analysis showed that this QTL region, along with a 3B QTL region are syntenic to chromosomal regions harbouring TaMFT-like genes. TaMFT is a homologue of the Arabidopsis $M F T$ gene which controls embryo-imposed seed dormancy and also regulates ABA and GA signal transduction [2,79]. These genes are members of the plant phosphatidylethanolamine binding protein (PEBP) family and are phylogenetically related to subfamilies, FLOWERING LOCUS T (FT)-like and TERMINAL FLOWER1 (TFL1)-like [80]. Where these genes show seed-specific expression [80], their ancestral relative $F T$ and TFL1, two flowering genes, act as molecular switches for reproductive development [81] in Arabidopsis, thus implying QPhs.lrdc-3A.1 to be a very important QTL.

Two other important QTLs detected on homeologous group 3 chromosomes were QPhs.lrdc-3D.1 and QPhs. lrdc-3D.2. Both of these QTLs explained similar PV (up to 10.0 and $12.0 \%$, respectively) and had similar LOD scores (up to 4.21 and 6.18, respectively), but they differed significantly for AE (up to 0.80 and 0.48 , respectively). Moreover, while the resistance allele at QPhs. lrdc-3D.1 was contributed by AAC Innova, resistance allele at QPhs.lrdc-3D.2 was contributed by AAC Tenacious. QPhs.lrdc-3D.1 was mapped to the same interval 


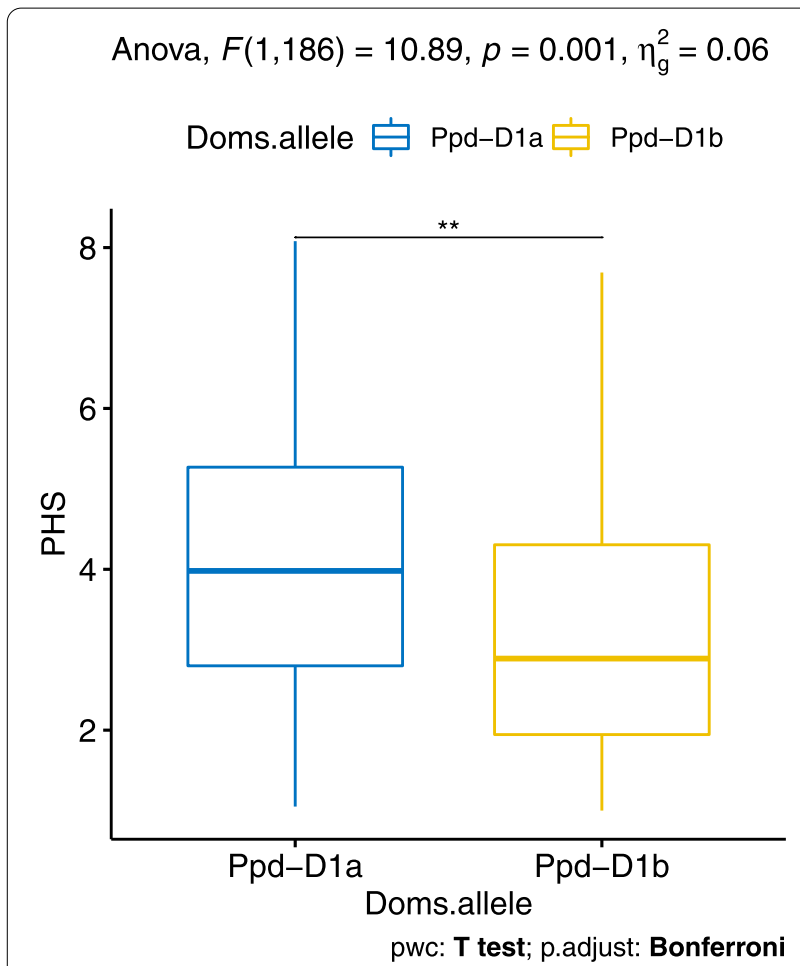

Fig. 5 Boxplot distributions of pre-harvest sprouting (PHS) score in population divided into photoperiod-insensitive vs -sensitive groups. All DH lines produced from the cross AAC Innova/AAC Tenacious were grouped into two genotypic classes, photoperiod-insensitive (Ppd-D1a) and -sensitive (Ppd-D1b), based on the domestication allele of the photoperiod gene Ppd-D1.Ppd-D1 is an important candidate gene for QPhs.Irdc-2D.1 QTL on chromosome 2D. Effects of domestication alleles of Ppd-D1 on average PHS score are presented using the pooled phenotypic data (average of all environments). Photoperiod-sensitive allele Ppd-D1b significantly reduced PHS in AAC Innova/AAC Tenacious DH population. Statistically significant difference between alleles is calculated by ANOVA, pairwise T test with Bonferroni corrections and shown by asterisk. Quartiles and medians are represented by boxes and continuous lines, respectively. Whiskers extend to the farthest points that are not outliers

as at least three previously reported QTLs, including PHS resistance QTL QPhs.cnl-3D.1 from US cv Cayuga [72], germination index QTL QGi.crc-3D from Canadian cv AC Domain [71], and a QTL at marker locus Xbarc376 in a germplasm line [70]. Interestingly, AAC Innova also shares its pedigree with AC Domain and US cv Cayuga, which have common PHS-resistant source landraces in their lineage like Hard Red Calcutta.

We have located homologs of three important genes, namely AGO802D, Reduced dormancy4 (RDO4)/Histone Monoubiquitination1 (HUB1) and Viviparous-1 (Vp1), in the physical interval of QPhs.lrdc-3D.1. All these candidate genes are known to influence seed dormancy through ABA-synthesis and -signal transduction pathway $[1,5,31,33,43,45]$. Furthermore, the 3B homolog of $A G O 802 D$ in wheat and barley, and HUB1 in Arabidopsis are believed to be involved in epigenetic changes that have a role in seed dormancy $[5,43,45]$. The role of ARGONAUTE (AGO) proteins in the DNA silencing through the RNA dependant DNA methylation pathway have previously been linked with seed dormancy in wheat [5]. Singh et al. [5] located three $A G O 802$ genes on group 3 chromosomes of wheat and found that $A G O 802-B$ on chromosome $3 \mathrm{~B}$ was associated with seed dormancy in six Canadian wheat cultivars/genotypes. During the present study, we found that the QTL intervals QPhs. lrdc-3A.2 (on chromosome 3A) and QPhs.lrdc-3D.1 (on chromosome 3D) are syntenic to the physical interval of $A G 0802-A$ and $A G 0802-D$, respectively. However, we could not locate $A G O 802-B$ to the PHS resistance QTL interval on 3B. It would be useful if the role of the two $A G O$ genes could be confirmed in the PHS resistance of AAC Tenacious. Another important candidate gene is histone methyltransferase $R D O 4 / H U B 1$, which positively regulates expression of Delay of germination 1 (DOG1), a gene which encodes a member of a plant specific protein family with a domain shared by the D class bZIP DNAbinding proteins $[45,82] . V p 1$ is another candidate in this QTL interval that encodes a transcription factor that regulates late embryo development in bread wheat [1]. It has been previously linked with seed dormancy and PHS resistance (reviewed in [1]). Expression of $V p 1$ in wheat embryos has been positively correlated with ABA sensitivity and degree of seed dormancy [31,33]. Splicing of the $V p 1$ gene in wheat resulted in susceptibility to PHS [33]. The TaVp1 genes were previously mapped around $30 \mathrm{cM}$ away from $R$ loci on group 3 chromosomes [29, $34,35] . V p 1$ could be an important regulator of PHS/seed dormancy in this QTL region of AAC Tenacious.

Second 3D QTL, QPhs.lrdc-3D.2, mapped to the 3D genomic interval where at least three QTLs have been previously mapped from different cultivars. These include PHS resistance QTL QPhs.inra-3D from French cv Renan [34], germination index QTL QGi.crc-3D from Canadian cv AC Domain [71] and TaMyb10-D1 using diverse germplasm [70]. AAC Tenacious shares its pedigree with AC Domain and the French cv Renan, both of which had Thatcher as a common ancestor. Moreover, the grain color gene TaMyb10-D1 was also located to the genomic interval of this QTL. It seems that QPhs.lrdc-3D.2 was associated with the expression of TaMyb10-D1 that regulates the key enzymes in the flavonoid pathway [58].

The seed coat restrict germination by its mechanical resistance to radicle protrusion or being impermeable to water and/or oxygen [83]. Seed coat properties, particularly the presence of phenolic compounds, positively correlate with seed coat color (reviewed in [1]). Red-grained 
wheat genotypes exhibit a wide range of seed dormancy and are more resistant to PHS than white-grained cultivars [84]. Grain color (GC) was found to be associated with seed dormancy and PHS resistance in many wheat cultivars previously and is controlled by the $R-1$ genes located on long arms of chromosomes $3 \mathrm{~A}, 3 \mathrm{~B}$, and $3 \mathrm{D}$ (reviewed in [1]), [84, 85]. Myb-type transcription factor loci (Tamyb10-A1, Tamyb10-B1, and Tamyb10-D1), which act as transcriptional activators for flavonoid synthesis pathway genes, have previously been found associated with seed dormancy and PHS resistance and are located in the same regions as the $R$ genes $[1,27,29,84$, 85]. Himi et al. [85] also confirmed the three Tamyb10-1 genes on chromosomes $3 \mathrm{AL}, 3 \mathrm{BL}$, and $3 \mathrm{DL}$ as candidate genes underlying the $R-1$ loci for wheat grain color. Since the AAC Innova/AAC Tenacious DH population also segregated for grain color, TaMyb10-D1 could be an important gene in $Q P h s . l r d c-3 D .2$ region.

Another QTL identified during this study is QPhs.lrdc4A. Though it explained 9.0\% PHS PV but was detected in Edmonton 2019, Ithaca 2018, Lethbridge 2018 and the pooled data. It had an AE up to 0.78 and a LOD score up to 6.14 (Table 1). The AAC Tenacious allele at this QTL reduced PHS by around $8.7 \%$. A number of QTLs, such as the major QTL Phs1 from Canadian cv. Leader and Japanese line OS21-5 [51, 52], QPhs.ocs-4A.1 and QDor-4A from Japanese cv. Zenkoujikomugi [57, 59], and a sprouting QTL from Mexican cv. Opata [61] have been mapped to the same region as of QPhs.lrdc-4A. AAC Tenacious shares its pedigree with Leader, OS21-5 and Opata, but not with Zenkoujikomugi. The major 4A QTL Phs1 in wheat is an ortholog of $S D 2(Q s d 2-A K)$ in barley $[52,86]$. Torada et al. [52] identified a mitogen-activated protein kinase kinase 3 (MKK3) gene (or TaMKK3-A) as a candidate gene for the seed dormancy QTL Phs1 on chromosome 4A in wheat. Abe et al. [86] developed a triple (for all homeologous loci)-knockout mutant of the Qsd1, another dormancy locus in barley, using CRISPR/Cas9 in wheat cv Fielder which also showed longer dormancy than the wild-type plants. However, a BLAST search of the complete mRNA sequence (GenBank: LC091369.1) of candidate gene TaMKK3-A resulted in no perfect match on chromosome 4A of IWGSC RefSeq v2.0 of wheat. Additional experiments are required to confirm the association of TaMKK3-A with QPhs.lrdc-4A.

Four other loci of great importance identified in this study are QPhs.lrdc-1A.2, QPhs.lrdc-2B.1, QPhs. lrdc-3B.2 and QPhs.lrdc-7D. Out of these, QPhs.lrdc1A.2 explained up to $14.0 \% \mathrm{PV}$ of PHS and also had a high LOD score of 6.7 (Table 1). Although the AE of this QTL was only 0.63 , it still reduced PHS by around $7.0 \%$. It mapped to the same interval where at least one QTL, QPhs.ccsu-1A.1, has been previously identified and mapped from Indian bread wheat cv HD2329 [58]. HD2329 also shared its pedigree with AAC Tenacious and traces back to different common cultivars such as Thatcher, Marquis, Hard Red Calcutta, Frontana, etc.

QPhs.lrdc-2B.1 explained 10.0\% of PHS PV, had a maximum AE (up to 1.43) on PHS and was detected in Edmonton 2019 and the pooled data (Table 1). The AAC Tenacious allele at this QTL reduced PHS by around $16.0 \%$. Interestingly, this QTL is being reported for the first time and does not seem to be homoeo-QTL or paralogue.

QPhs.lrdc-3B.2 explained up to $13.0 \% \mathrm{PV}$ and had an $\mathrm{AE}$ of 0.59 detected at a high LOD score of 7.20. The resistance allele at this QTL was contributed by AAC Tenacious and reduced PHS up to 6.5\%. Like QPhs.lrdc$2 B .1$, it is a new PHS resistance QTL being reported for the first time. It was detected in Ithaca 2018, Lethbridge 2019, and the pooled data, and like QPhs.lrdc-2B.1, is considered a new, major and relatively stable QTL. Resistance allele at this QTL was contributed by AAC Tenacious.

QPhs.lrdc-7D explained up to $18.0 \% \mathrm{PV}$ and had a LOD score $>6.0$ and an $\mathrm{AE}$ of 1.20. Interestingly, the resistance allele at this locus was contributed by AAC Innova and it was detected in Lethbridge 2019 and the pooled data. The AAC Innova allele at this locus reduced sprouting by around $13.0 \%$. A falling number QTL, namely QFn.crc-7D, in the same region of this QTL on chromosome 7D has been previously reported from the Canadian wheat cultivar AC Domain [73]. The discovery of this QTL in AAC Innova is not unexpected as both AAC Innova and AC Domain share their early Canadian wheat lineage through the PHS resistance source cv Hard Red Calcutta [54].

QTLs QPhs.lrdc-1A.3 (AE: up to 0.62, LOD score: up to 5.14 and PVE: up to 9.0\%) and QPhs.lrdc-3A.2 (AE: up to 0.84 , LOD score: up to 4.82 and PVE: $9.0 \%$ ) are also important. QTLs/markers have been previously repeatedly mapped in genomic regions of these QTLs utilizing diverse germplasm, and Indian and Japanese lines/ cvs with either no information or unrelated pedigrees (Table 2) [58, 60, 70]. This indicates that the identified QTLs can be utilized in different genetic backgrounds/ geographical areas for improving PHS as an adaptive trait.

In addition to the above-mentioned QTLs, a number of other QTLs such as QPhs.lrdc-2A, QPhs.lrdc-2D.1, QPhs.lrdc-3B.1, QPhs.lrdc-4B and QPhs.lrdc-5A.1 had relatively less effect on PHS resistance (Table 1 ) and were considered minor suggestive loci $[77,78]$. However, PHS resistance QTLs/genes have been previously identified in genomic regions of these QTLs from different genotypes (Table 2) such as SPR8198 (India, unknown pedigree), Danby (USA, shared pedigree with AAC Tenacious), RSP 
(China; PHS resistance derived from Aegilops tauschii [87]), AC Domain (Canada, shared pedigree with AAC Tenacious) and Chinese Spring (China, susceptible [57, 88] cultivar with unrelated pedigree) [12, 56-58, 71]. Therefore, these regions can also be of regional and/ or global utility. For instance, $P p d-D 1$, a photoperiod response and domestication gene, was located to the genomic interval of QPhs.lrdc-2D.1. Genotyping of the whole DH population with functional marker of domestication/photoperiod response gene $P p d-D 1$ showed that AAC Innova had a photoperiod-insensitive allele $P p d$ D1a, while AAC Tenacious had the photoperiod-sensitive allele $P p d-D 1 b$ [75]. It was observed that the AAC Tenacious derived photoperiod-sensitive allele $P p d-D 1 b$ significantly reduced pre-harvest sprouting in the AAC Innova/AAC Tenacious population, irrespective of other genes/QTLs (Fig. 5). This gene can be utilized to improve PHS resistance using marker-assisted selection in wheat cultivars for geographical areas where longer photoperiods occur over wheat growing season.

Knowing that the maturity date, which can be affected by Ppd-D1 [89], would affect the PHS resistance [90], it is intriguing to know whether PHS resistance in QPhs. $l r d c-2 D .1$ region is a function of maturity date or a direct effect of Ppd-D1. However, we did not record the maturity date on this population, DTA data was available from one [75] of our previous studies on this population and used for correlation coefficient $(r)$ analysis with PHS data. DTA showed weak negative $(r-0.20)$ association with PHS. Moreover, our group recently mapped a DTA QTL [75] to same chromosomal region as QPhs.lrdc-2D.1 in AAC Innova/AAC Tenacious population. Although it is difficult to draw firm conclusions about the effect of maturity date utilizing available datasets without further investigation, our results and previous findings [75] suggest that PHS resistance at QPhs.lrdc-2D.1 is perhaps influenced by DTA and the later conditions this population was exposed to during grain development stages. It is known that a semi-dominant mutation in the promoter region of the $P p d-D 1$ gene, which transforms long day wheat to day neutral (photoperiod insensitive) and provides adaptation to a wide range of environments, was widely used in the "green revolution" [91]. Our results are in agreement with previous observations that domestication played a role in the loss of seed dormancy and changes in photoperiod sensitivity, two of the several common features of "domestication syndrome" $[63,66$, 92-94].

\section{Conclusion}

This study showed the complexity of PHS resistance in AAC Tenacious. Multiple PHS resistance loci, including some major QTLs, were identified from AAC Tenacious in comparison to only a few from AAC Innova. However, AAC Innova also contributed two major QTLs with most of the QTLs being unstable (detected in single environment) except minor QTL QPhs.lrdc-2B.2. Therefore, pyramiding of major PHS resistance loci from both parents as source cultivars could significantly improve PHS resistance in future wheat cultivars. Moreover, around two-third (13) of identified loci were mapped to the chromosomal regions of previously identified QTLs. These common regions included some QTLs detected repeatedly during previous studies, such as QPhs.lrdc-3A.1 and QPhs.lrdc-4A regions on chromosomes $3 \mathrm{~A}$ and $4 \mathrm{~A}$, respectively. The tracing of pedigrees of AAC Tenacious and other sources complements the validation of QTL analysis results. Some of the PHS resistance QTLs have been cloned previously and a few of those, as discussed above, have also been physically located in the QTL intervals of the present study. By comparing our results with previous PHS studies in wheat, we have confirmed the position of many major PHS resistance QTLs and candidate genes. Despite the presence of such a great reservoir of important QTLs/genes in AAC Tenacious, many identified QTLs were detected in unique environments. This might be contributed by the high level of environmental effect, which requires the validation of environment-specific QTLs first before employing them in breeding programs.

\section{Method}

\section{Plant material}

A spring wheat recombinant doubled haploid mapping population (224 lines) was developed by crossing AAC Innova [76] as the female with AAC Tenacious as the male, followed by haploid induction using the wheatmaize pollination technique [95] at the Agriculture and Agri-Food Canada, Lethbridge Research and Development Centre (LeRDC), Lethbridge, AB, Canada. AAC Innova is a PHS susceptible, white-grained, semi-dwarf, soft white spring type cultivar which belongs to Canada Western Special Purpose market class. AAC Tenacious is a highly PHS resistant, red-grained, tall, hard red spring type cultivar which belongs to Canada Prairie Spring market class. AAC Innova originated from the cross AC Andrew/N9195 made at LeRDC in 2001 and developed using a modified bulk breeding technique [76]. AAC Tenacious was developed from the cross HY665/BW346 made at the Agriculture and Agri-Food Canada, Cereal Research Centre (CRC), Winnipeg, Manitoba during the winter of 2003-2004 [68].

A number of soft-white and hard-red spring wheat cvs belonging to different market classes and with varying levels of PHS resistance were used as checks for comparisons (Table 3). 
Seeds of cultivars used as checks and parents of the mapping population were accessed from Spring Wheat Breeding core collection at AAFC-LeRDC. DH lines produced in this study are preserved at AAFC-LeRDC and available upon request. All other cultivars used in this study are preserved at Plant Gene Resources of Canada (PGRC) seed genebank based at AAFC's Saskatoon Research and Development Centre, Saskatoon, Saskatchewan, Canada.

\section{Trial environments and pre-harvest sprouting assessment}

The recombinant doubled haploid lines, their parents and check cultivars were grown in field conditions in four environments: (i) University of Alberta, Edmonton, Canada in 2019 (EDM 2019), (ii) Cornell University, Ithaca, USA in 2018 (ITH 2018), (iii) LeRDC, Lethbridge, Canada in 2018 (LET 2018), and (iv) LeRDC, Lethbridge, Canada in 2019 (LET 2019). PHS resistance assessment at Cornell University, Ithaca, USA was carried out following Anderson et al. [112] and Munkvold et al. [72]. At the Edmonton and Lethbridge locations, PHS resistance assessment was carried out following Anderson et al. [112] and Paterson et al. [113] with some modifications. Mature heads of each genotype (recombinant DHs, parents and check cultivars) were harvested from the field trials at physiological maturity (+1 week), when most of the nodes collapsed in the plot. For each genotype, 15 heads (as 3 bundles, each of 5) were harvested. Harvested heads were spread out on benches in a greenhouse and left for 2 days at room temperature to dry. The dried heads were then stored at $-20^{\circ} \mathrm{C}$ until assessments were undertaken.

For PHS resistance assessments, heads were removed from the $-20^{\circ} \mathrm{C}$ cold room in the morning and kept at room temperature for $2 \mathrm{~h}$ followed by soaking in doubledistilled water in plastic containers for another $2 \mathrm{~h}$. After soaking, head bundles of DH lines along with their parents and checks were mounted upright on black plastic trays fixed on wire grid in a mist-chamber where they were moistened thoroughly from fixed spray nozzles. The mist-chamber was set at: $100 \%$ relative humidity, $25^{\circ} \mathrm{C}$ and no light.

Sprouting was visually assessed on a daily basis in the mist chamber. When the sprouting distinguished both parents and the check cultivars by a maximum difference (when susceptible parent AAC Innova and check cultivars largely stopped sprouting new grains), head bundles were removed from the mist chamber and assessed for PHS. On average, the maximum difference was seen on 5 th day. Thus, the wet head bundles were removed from the mist-chamber on the morning of day 5 , and each bundle was assessed for the number of heads with different numbers of sprouts as follows:

$a=$ \# heads with 0 sprouts $b=$ \# heads with 1 sprout

$c=\#$ heads with 2 sprouts

$d=$ \# heads with $3-5$ sprouts

$e=\#$ heads with $>6-10$ sprouts

$f=$ \# heads with $10+$ sprouts

$g=$ \# total heads evaluated ( 5 in this case)

Using the numbers calculated above for bundles (reps), the bundle (rep) pre-harvest sprouting resistance $\left(\mathrm{PHSR}_{\mathrm{n}}\right)$ scores were calculated using weighted parameters given in DePauw et al. [114] as follows:

$$
\text { PHSRn }=\frac{(a) 1+(b) 2+(c) 3+(d) 5+(e) 7+(f) 9}{g}
$$

Genotype PHSR score was calculated by averaging individual bundle scores as follows:

$$
P H S R=\frac{\left(P_{H S R_{1}}\right)+\left(\text { PHSR }_{2}\right)+\left(\text { PHSR }_{3}\right)}{3}
$$

Using the above formula, the best PHS resistant line was rated as PHSR score 1 while the worst as PHSR score 9.

\section{Statistical analysis}

All the statistical analyses were carried out using various software packages in R (version 3.2.3) [115], the software environment for statistical computing and graphics. For the ANOVA model, DHs, their parents and check cultivars were considered fixed effects, while environments were considered random effects. Mixed ANOVA and post-hoc tests, and visualization of results in graphical forms were carried out using $\mathrm{R}$ packages tidyverse (version 1.2.1) [116], ggpubr (version 0.4.0) [117] and rstatix (version 0.6.0) [118] following Kassambara [119]. TypeII analysis of variance of PHS data was calculated both within and across environments using the agricolae (version 1.2-4) package [120]. To counter the missing values, type-III analysis of variance was calculated using Satterthwaite's method with the package 'ImerTest' [121]. Correlations and regression analyses among environments and scatterplots were calculated using the $\mathrm{R}$ package GGally [122].

\section{Quantitative trait loci analysis}

QTL analysis was carried out using the previously developed AAC Innova/AAC Tenacious linkage map [75] from $188 \mathrm{DH}$ lines and phenotypic data collected from four environments mentioned above following Dhariwal et al. [123]. Briefly, main effect QTLs were identified using the composite interval mapping (CIM) approach with the regression method forwards and backwards cofactor $(p=0.05)$ implemented in QTL 
Table 3 Details of check cultivars used for comparison of pre-harvest sprouting (PHS) resistance

\begin{tabular}{|c|c|c|c|c|}
\hline Cultivar & Type & Pedigree & Origin & Reference \\
\hline AAC Awesome & Soft white spring & 93FHB37/2*Andrew//SWS366 & AAFC-LeRDC & {$[96]$} \\
\hline AAC Chiffon & Soft white spring & AC Reed/SWS53 & AAFC-LeRDC & {$[97]$} \\
\hline AAC Indus & Soft white spring & Sadash/SWS340 & AAFC-LeRDC & [98] \\
\hline AC Andrew & Soft white spring & Dirkwin/SC8021V2//Treasure/Blanca & AAFC-LeRDC & [99] \\
\hline Sadash & Soft white spring & SWS207/SWS208//SWS214 & AAFC-LeRDC & {$[100]$} \\
\hline AAC Foray & Hard red spring & CPS03hnF4 5123.032/5701PR & AAFC-CRC & [101] \\
\hline Cardale & Hard red spring & McKenzie/Alsen & AAFC-CRC & {$[102]$} \\
\hline Conquer & Hard red spring & HY639/99 EPWA-Mdg61 & AAFC-CRC & [103] \\
\hline Enchant & Hard red spring & 97-M-27/AC Vista & AAFC-CRC & {$[104]$} \\
\hline Lillian & Hard red spring & $\mathrm{BW} 621 * 3 / 90 \mathrm{~B} 07-\mathrm{AU} 2 \mathrm{~B}$ & AAFC-CRC AAFC-SCRDC & {$[105]$} \\
\hline Vesper & Hard red spring & $\begin{array}{l}\text { Augusta/Hard White Alpha//3*AC Barrie/BW150*2// } \\
\mathrm{Tp} / \mathrm{Tm} / 3 / 2^{*} \text { Superb/4/94B35-R5C/5/Superb }\end{array}$ & AAFC-CRC & [106] \\
\hline AAC Brandon & Hard red spring & Superb/CDC Osler//ND744 & AAFC-SCRDC & [107] \\
\hline AAC Penhold & Hard red spring & 700PR/HY644-BE//HY469 & AAFC-SCRDC & [108] \\
\hline Carberry & Hard red spring & Alsen/Superb & AAFC-SCRDC & [109] \\
\hline Stettler & Hard red spring & Prodigy/Superb & AAFC-SCRDC & {$[110]$} \\
\hline CDC Stanley & Hard red spring & W95132/AC Barrie & CDC-UofS & {$[111]$} \\
\hline
\end{tabular}

Note: AAFC-Agriculture and Agri-Food Canada, CRC Cereal Research Centre (CRC), Winnipeg, Manitoba, LeRDC Lethbridge Research and Development Centre, Lethbridge, Alberta, SCRDC Swift Current Research and Development Centre, Swift Current, Saskatchewan, CDC Crop Development Centre, University of Saskatchewan, Saskatoon, Saskatchewan

Cartographer (version 1.6) $[124,125]$. QTL thresholds were estimated using 1000 permutations at a significance level of $p=0.05$. QTLs detected in at least one environment or the pooled data but had LOD score $\geq 2.5$ were also reported. LOD peak spanning chromosome interval above the threshold/selected score were used to determine QTL intervals. LOD score thresholds were 3.1 at Edmonton 2019, 3.0 at Ithaca 2018, 3.4 at Lethbridge 2018, 3.4 at Lethbridge 2019, and 3.3 for the pooled data. Marker intervals that harboured two or more QTLs within $10.0 \mathrm{cM}$ were considered as a single QTL region, while the rest of the QTL intervals (> 10.0 cM apart) were considered unique QTL regions [75]. Mixed-model based composite interval mapping (MCIM) to map main effect QTLs and two-locus QTL analysis to map epistatic QTLs were carried out using QTLNetwork (version 2.0) [126] following Dhariwal et al. [127]. QTL analyses results were represented as a Circos diagram using the $\mathrm{R}$ package OmicCircos (version 1.14.0) [128].

\section{Assignment of physical intervals and mapping of candidate genes}

Wheat $90 \mathrm{~K}$ iSelect SNP assay probe sequences of all the SNP markers that mapped into QTL intervals in this study were BLAST searched (with at least 99\% identity and $100 \%$ query coverage) against the wheat reference genome (IWGSC RefSeq v2.0) sequence using NCBI standalone BLAST program [129] to identify the physical interval on wheat chromosomes. Primer/probe sequences of flanking/linked markers of QTLs, identified previously from different genotypes during different studies as well as the gDNA/cDNA sequences of cloned PHS or dormancy related genes (Additional file 2: Table S9), were also BLAST searched against the wheat reference genome to identify common/shared QTL regions and candidate genes among different studies.

\section{Validation and assessment of the effect of Ppd-D1 on PHS resistance}

Associations of days to anthesis (DTA) and the two alleles (insensitive, $P p d-D 1 a$ and sensitive, $P p d-D 1 b$ ) of domestication/photoperiodic response gene $P p d-D 1$ with PHS resistance were assessed using correlation coefficient and boxplot analyses, respectively.

\section{Pedigree and genealogical analysis}

Pedigrees of AAC Tenacious, AAC Innova, and other source cultivars were traced using the information from literature sources extracted from the 'GRIS: Genetic Resources Information System for Wheat and Triticale' database [130] (accessed: November 1-25, 2020), 'UK wheat varieties pedigree' dataset [131, 132], and publications by Martynov and Dobrotvorskaya [54], Osanai et al. [133] and Garlinge [134]. A color coded complete pedigree of AAC Tenacious was graphically generated using Helium Pedigree Visualization Framework [135]. 


\section{Abbreviations}

AA: Additive $x$ additive effect or epistasis interaction effect; AAC: Prefix to cultivar names Agriculture Canada (Agriculture and Agri-Food Canada); AAFC: Agriculture and Agri-Food Canada; ABA: Abscisic acid; ABI3: Abscisic acid insensitive3; AC: Prefix to cultivar names Agriculture Canada (Agriculture and Agri-Food Canada); AGO: Argonaute; ANOVA: Analysis of variance; BLAST: Basic local alignment search tool; bZIP: Basic leucine zipper domain; CDC: Crop Development Centre; cDNA: Complementary deoxyribonucleic acid; $\mathrm{CHI}$ : Chalcone isomerase; CHS: Chalcone synthase; CIM: Composite interval mapping; CM: Centimorgan, a linkage map unit; CPS: Canada Prairie Spring wheat class; CRC: Cereal Research Centre, Winnipeg, Manitoba; CRISPR/Cas9: Clustered regularly interspaced short palindromic repeats and CRISPR-associated protein 9; CWSP: Canada Western Special Purpose wheat class; cv: Cultivar; cvs: Cultivars; CYP: Cytochromes P450 superfamily of enzymes; DH: Doubled haploid; DNA: Deoxyribonucleic acid; DOG1: Delay of germination 1; Dor: Dormancy; EDM: Edmonton; Fn: Falling number; FT: Flowering locus T; F3H: Flavanone 3-hydroxylase; GA: Gibberellic acid or gibberellin; GC: Grain color/colour; gDNA: Genomic deoxyribonucleic acid; Gl: Germination index; HUB1: Histone monoubiquitination 1; ITH: Ithaca; IWGSC: International Wheat Genome Sequencing Consortium; LET: Lethbridge; LG: Linkage group; LOD: Logarithm of the odds; LeRDC: Lethbridge Research and Development Centre, AB, Canada; Irdc: Lethbridge Research and Development Centre, AB, Canada; MCIM: Mixed-model based composite interval mapping; MFT: Mother of FT and TFL1; MKK: Mitogenactivated protein kinase kinase; MR: Moderately resistant; MS: Moderately susceptible; Myb: Myeloblastosis family of transcription factor gene; NCBI: National Center for Biotechnology Information; PEBP: Plant phosphatidylethanolamine binding protein family; PHS: Pre-harvest sprouting; PHSR: Pre-harvest sprouting resistance; PHT: Plant height; PM: Plasma membrane; Ppd: Photoperiod responsive; PV: Phenotypic variation; PVE: Phenotypic variation explained; QPhs: Quantitative trait loci for pre-harvest sprouting; QTL: Quantitative trait loci; R: Resistant/Resistant gene/Resistance; $r$ : Correlation coefficient; $R^{2}$ : Phenotypic variation; RdDM: RNA dependant DNA methylation pathway; RDO: Reduced dormancy; RefSeq: Reference Sequence; Rht: Reduced height gene; RSP: Name of a Chinese wheat landrace; S: Susceptible; SCRDC: Swift Current Research and Development Centre, Swift Current, Saskatchewan; SD: Seed dormancy; Sdr: Seed dormancy gene; SNP: Single nucleotide polymorphism; SSR: Simple sequence repeat; Ta: Triticum aestivum; TFL1: Terminal Flower1; UofS: University of Saskatchewan, Saskatoon, Saskatchewan; USA: The United States of America; USD: United States Dollar; v: Version; Vp: Viviparous.

\section{Supplementary Information}

The online version contains supplementary material available at https://doi. org/10.1186/s12864-021-08209-6.

Additional file 1: Figure S1. Pre-harvest sprouting (PHS) phenotypes of check cultivars after 4 days in a mist chamber. Spike bundles from left to right of resistant (Cardale, Enchant, Stettler, AAC Tenacious, Penhold, CDC Stanley), intermediate (Vesper, AAC Indus, Carberry, Lillian, AAC Chiffon, AAC Brandon, AAC Foray) and susceptible (Sadash, AAC Innova, AAC Awesome, Conquer, AC Andrew) cultivars are shown in upper, middle and lower rows, respectively.

Additional file 2: Tables S1 to S9. Details of pre-harvest sprouting data, quantitative trait loci, associated markers, genetic/genomic positions, and previous studies.

Additional file 3: Figure S2. Effects of pre-harvest sprouting (PHS) resistance quantitative trait loci (QTLs) on sprouting. Effects of QTLs QPhs. Irdc-1A.2, QPhs.Irdc-2B.1, QPhs.Irdc-3A.1, QPhs.Irdc-3B.2, QPhs.Irdc-3D.1, QPhs. Irdc-3D.2 and QPhs.Irdc-7D, respectively, shown as 1A.2, 2B.1, 3A.1, 3B.2, 3D.1, 3D.2 and 7D, are presented as bar plot and line graph.

Additional file 4: Figure S3. Complete pedigree of wheat cultivar AAC Tenacious. Different cultivars/landraces and their crosses in pedigree are shown in circles. Female and male parents are shown by pink and blue line connections. Circle colors dark green, light green, dark red, light red, dark amber and light amber represents pre-harvest sprouting (PHS) resistant progenitors of AAC Tenacious. Blue, light blue and gray circles represents other cultivars and crosses in the pedigree.

Additional file 5. Pedigree information of different wheat genotypes of different origin.

\section{Acknowledgements}

We gratefully acknowledge the financial support provided by Alberta Wheat Commission and AAFC Canadian National Wheat Cluster Program. We greatly acknowledge the technical support provided by Leslie Bihari and Zafrin Akter in production of doubled haploid population, and help received in phenotyping by Mark Virginallo. We also acknowledge the support of Klaus Strenzke (University of Alberta, Edmonton) and Mark Virginallo, Kelly Ryan, and Kim Ziegler (Lethbridge Research and Development Centre, Lethbridge) in the field experiments.

\section{Authors' contributions}

HSR developed the genetic mapping population. RD and HSR designed the study. HSR, MES and DS grown the mapping population in Lethbridge, Ithaca and Edmonton, respectively. RD and MES phenotyped the mapping population. $\mathrm{CH}$ genotyped the mapping population. RG provided the pedigree information of AAC Tenacious. RD performed all analyses, interpreted the results and writing of the original draft. All authors read and approved the final manuscript.

\section{Authors' information}

$\mathrm{RD}$ is a Research Biologist and CH, RJG and HSR are Research Scientists at Agriculture and Agri-Food Canada. MES and DS are Professors at Cornell University, USA and University of Alberta, Canada, respectively. JS is an Associate Professor at McGill University, Canada.

\section{Funding}

This research was funded by Alberta Wheat Commission and AAFC Canadian National Wheat Cluster Program.

\section{Availability of data and materials}

Linkage map of AAC Innova/AAC Tenacious doubled haploid mapping population of spring wheat, which is used for the present study, has been published previously by authors (Dhariwal et al. [75]; https://doi.org/10.3390/ ijms21124497). Linkage map is publically available as supplementary information of the published paper [75] and can either be downloaded from the link: https://www.mdpi.com/1422-0067/21/12/4497\#supplementary or requested from the corresponding author. All other data generated or analysed during this study are included in this published article and its supplementary information files.

\section{Declarations}

Ethics approval and consent to participate

The use of plant parts in the present study complies with international, national and/or institutional guidelines.

\section{Consent for publication}

Not applicable.

\section{Competing interests}

The authors declare that they have no competing interests.

\section{Author details}

${ }^{1}$ Lethbridge Research and Development Centre, Agriculture and Agri-Food Canada, 5403 1st Avenue South, Lethbridge, AB T1J 4B1, Canada. ${ }^{2}$ Morden Research and Development Centre, Agriculture and Agri-Food Canada, 101 Route 100, Morden, MB R6M 1Y5, Canada. ${ }^{3}$ School of Integrative Plant Science, Plant Breeding and Genetics Section, Cornell University, 240 Emerson Hall, Ithaca, NY 14853, USA. ${ }^{4}$ Department of Agricultural, Food \& Nutritional Science, University of Alberta, Edmonton, AB T6G 2P5, Canada. ${ }^{5}$ Department of Plant Science, McGill University, Ste-Anne-de-Bellevue, QC H9X 3V9, Canada.

Received: 15 February 2021 Accepted: 11 November 2021 Published online: 15 December 2021 


\section{References}

1. Ali A, Cao J, Jiang H, Chang C, Zhang H-P, Sheikh SW, et al. Unraveling molecular and genetic studies of Wheat (Triticum aestivum L.) resistance against factors causing pre-harvest sprouting. Agronomy. 2019;9(3):117.

2. Nakamura S, Abe F, Kawahigashi H, Nakazono K, Tagiri A, Matsumoto T, et al. A wheat homolog of MOTHER OF FT AND TFL1 acts in the regulation of germination. Plant Cell. 2011;23(9):3215-29.

3. Morgan G. Pre-harvest sprouting in wheat. In: Texas Co-operative Extension E-336; 2005

4. Torada A, Ikeguchi S, Koike M. Mapping and validation of PCR-based markers associated with a major QTL for seed dormancy in wheat. Euphytica. 2005;143(3):251-5.

5. Singh M, Singh S, Randhawa $H$, Singh J. Polymorphic homoeolog of key gene of RdDM pathway, ARGONAUTE4_9 class is associated with pre-harvest sprouting in wheat (Triticum aestivum L.). PLoS One. 2013:8(10):e77009.

6. Kocheshkova AA, Kroupin PY, Bazhenov MS, Karlov Gl, Pochtovyy AA, Upelniek VP, et al. Pre-harvest sprouting resistance and haplotype variation of ThVp-1 gene in the collection of wheat-wheatgrass hybrids. PLoS One. 2017:12(11):e0188049.

7. Zhang Y, Miao X, Xia X, He Z. Cloning of seed dormancy genes (TaSdr) associated with tolerance to pre-harvest sprouting in common wheat and development of a functional marker. Theor Appl Genet. 2014;127(4):855-66.

8. Nakamura S. Grain dormancy genes responsible for preventing preharvest sprouting in barley and wheat. Breed Sci. 2018;68(3):295-304.

9. Derera NF. A perspective of sprouting research. In: Fifth international symposium on pre-harvest sprouting in cereals: 1990. Colorado: Westview Press; 1990. p. 3-11.

10. Clarke FR, Clarke JM, DePauw RM, Fernandez MR, Fox S, Gilbert J, et al. Strategic approach to mitigating weather induced defects of wheat quality. Euphytica. 2005;143(3):285-90.

11. Singh R. Identification and validation of genomic regions associated with pre-harvest sprouting resistance in white-grained wheat (Triticum aestivum L.). Saskatoon: University of Saskatchewan; 2008

12. Shao M, Bai G, Rife TW, Poland J, Lin M, Liu S, et al. QTL mapping of pre-harvest sprouting resistance in a white wheat cultivar Danby. Theor Appl Genet. 2018;131(8):1683-97.

13. Imtiaz M, Ogbonnaya FC, Oman J, van Ginkel M. Characterization of quantitative trait loci controlling genetic variation for Preharvest sprouting in synthetic backcross-derived Wheat lines. Genetics. 2008:178(3):1725-36.

14. Yu N, Laurenz R, Siler L, Ng PKW, Souza E, Lewis JM. Evaluation of a-amylase activity and falling number around maturity for soft white and soft red Wheat varieties in Michigan. Cereal Res Commun. 2015;43(4):672-81.

15. Humphreys DG, Noll J. Methods for characterization of preharvest sprouting resistance in a wheat breeding program. Euphytica. 2002;126(1):61-5

16. Nagao S. Detrimental effect of sprout damage on wheat flour products. In: Seventh symposium on preharvest sprouting in cereals: 1995. Osaka: Center for Academic Societies; 1995. p. 3-8.

17. Derera NF. The effects of preharvest rain. In: Derera NF, editor. Preharvest sprouting in cereals. Boca Raton: CRC Press Inc; 1989. p. 2-14.

18. Kruger JE. Biochemistry of preharvest sprouting in cereals. In: Derera NF, editor. Preharvest sprouting in cereals. Boca Raton: CRC Press Inc; 1989. p. 61-84.

19. Derera NF, Bhatt GM. Germination inhibition of the bracts in relation to pre-harvest sprouting tolerance in wheat. Cereal Res Commun. 1980:8(1):199-201.

20. Gatford KT, Eastwood RF, Halloran GM. Germination inhibitors in bracts surrounding the grain of Triticum tauschii. Funct Plant Biol. 2002;29(7):881-90.

21. Krupnov VA, Antonov GY, Druzhin AE, Krupnova OV. Preharvesting sprouting resistance of spring bread wheat carrying the 6Agi(6D) chromosome from Agropyron intermedium. Russ J Genet. 2012;2(6):467-72

22. Flintham JE. Different genetic components control coat-imposed and embryo-imposeddormancy in wheat. Seed Sci Res. 2000;10(1):43-50.

23. Miyamoto T, Everson EH. Biochemical and physiological studies of wheat grain pigmentation. Agron J. 1958;50:733-4.
24. Stoy $V$, Sundin $K$. Effects of growth regulating substances in cereal grain germination. Cereal Res Commun. 1976;4:157-63.

25. Miyamoto T, Everson EH. Biochemical and physiological studies of wheat seed pigmentation. Agron J. 1958;50(12):733-4.

26. Kohyama N, Chono M, Nakagawa H, Matsuo Y, Ono H, Matsunaka $H$. Flavonoid compounds related to seed coat color of wheat. Biosci Biotechnol Biochem. 2017:81(11):2112-8.

27. Himi E, Mares DJ, Yanagisawa A, Noda K. Effect of grain colour gene (R) on grain dormancy and sensitivity of the embryo to abscisic acid (ABA) in wheat. J Exp Bot. 2002;53(374):1569-74.

28. Metzger RJ, Silbaugh BA. Location of genes for seed coat color in Hexaploid Wheat, Triticum aestivum L. Crop Sci. 1970;10(5):495-6.

29. Himi $E$, Noda K. Red grain colour gene (R) of wheat is a Myb-type transcription factor. Euphytica. 2005;143(3):239-42.

30. Gubler F, Millar AA, Jacobsen JV. Dormancy release, ABA and preharvest sprouting. Curr Opin Plant Biol. 2005;8(2):183-7.

31. Nakamura S, Toyama T. Isolation of a VP1 homologue from wheat and analysis of its expression in embryos of dormant and non-dormant cultivars. J Exp Bot. 2001;52(357):875-6.

32. Giraudat J, Hauge BM, Valon C, Smalle J, Parcy F, Goodman HM. Isolation of the Arabidopsis ABI3 gene by positional cloning. Plant Cell. 1992:4(10):1251-61.

33. McKibbin RS, Wilkinson MD, Bailey PC, Flintham JE, Andrew LM, Lazzeri PA, et al. Transcripts of Vp 1 homeologues are misspliced in modern wheat and ancestral species. Proc Natl Acad Sci. 2002;99(15):10203-8.

34. Groos C, Gay G, Perretant MR, Gervais L, Bernard M, Dedryver F, et al. Study of the relationship between pre-harvest sprouting and grain color by quantitative trait loci analysis in a white $\times$ red grain breadwheat cross. Theor Appl Genet. 2002;104(1):39-47.

35. Yang Y, Zhao XL, Xia LQ, Chen XM, Xia XC, Yu Z, et al. Development and validation of a Viviparous-1 STS marker for pre-harvest sprouting tolerance in Chinese wheats. Theor Appl Genet. 2007;115(7):971-80.

36. Barrero JM, Cavanagh C, Verbyla KL, Tibbits JFG, Verbyla AP, Huang BE, et al. Transcriptomic analysis of wheat near-isogenic lines identifies PM19-A1 and A2 as candidates for a major dormancy QTL. Genome Biol. 2015;16(1):93

37. Okamoto M, Kuwahara A, Seo M, Kushiro T, Asami T, Hirai N, et al. CYP707A1 and CYP707A2, which encode abscisic acid 8'-hydroxylases, are indispensable for proper control of seed dormancy and germination in Arabidopsis. Plant Physiol. 2006;141(1):97-107.

38. Liu A, Gao F, Kanno Y, Jordan MC, Kamiya Y, Seo M, et al. Regulation of wheat seed dormancy by after-ripening is mediated by specific transcriptional switches that induce changes in seed hormone metabolism and signaling. PLoS One. 2013;8(2):e56570.

39. Lei L, Zhu X, Wang S, Zhu M, Carver BF, Yan L. TaMFT-A1 is associated with seed germination sensitive to temperature in winter wheat. PLoS One. 2013;8(9):e73330.

40. Ashikawa I, Mori M, Nakamura S, Abe F. A transgenic approach to controlling wheat seed dormancy level by using Triticeae DOG1-like genes. Transgenic Res. 2014;23(4):621-9.

41. Murphey M, Kovach K, Elnacash T, He H, Bentsink L, Donohue K. DOG 1imposed dormancy mediates germination responses to temperature cues. Environ Exp Bot. 2015;112:33-43.

42. Liu S, Sehgal SK, Li J, Lin M, Trick HN, Yu J, et al. Cloning and characterization of a critical regulator for preharvest sprouting in wheat. Genetics. 2013;195(1):263-73.

43. Singh M, Singh J. Seed development-related expression of ARGONAUTE4_9 class of genes in barley: possible role in seed dormancy. Euphytica. 2012;188(1):123-9.

44. Zheng J, Chen F, Wang Z, Cao H, Li X, Deng X, et al. A novel role for histone methyltransferase KYP/SUVH4 in the control of Arabidopsis primary seed dormancy. New Phytol. 2012;193(3):605-16.

45. Liu Y, Koornneef M, Soppe WJ. The absence of histone H2B monoubiquitination in the Arabidopsis hub1 (rdo4) mutant reveals a role for chromatin remodeling in seed dormancy. Plant Cell. 2007;19(2):433-44.

46. Chen L-T, Luo M, Wang Y-Y, Wu K. Involvement of Arabidopsis histone deacetylase HDA6 in ABA and salt stress response. J Exp Bot. 2010;61(12):3345-53.

47. Chen L-T, Wu K. Role of histone deacetylases HDA6 and HDA 19 in ABA and abiotic stress response. Plant Signal Behav. 2010:5(10):1318-20. 
48. Demetriou K, Kapazoglou A, Tondelli A, Francia E, Stanca MA, Bladenopoulos K, et al. Epigenetic chromatin modifiers in barley: I. cloning, mapping and expression analysis of the plant specific HD2 family of histone deacetylases from barley, during seed development and after hormonal treatment. Physiol Plant. 2009;136(3):358-68.

49. Liu S, Bai G. Dissection and fine mapping of a major QTL for preharvest sprouting resistance in white wheat Rio Blanco. Theor Appl Genet. 2010;121(8):1395-404.

50. Liu S, Cai S, Graybosch R, Chen C, Bai G. Quantitative trait loci for resistance to pre-harvest sprouting in US hard white winter wheat Rio Blanco. Theor Appl Genet. 2008;117(5):691-9.

51. Torada A, Koike M, Ikeguchi S, Tsutsui I. Mapping of a major locus controlling seed dormancy using backcrossed progenies in wheat (Triticum aestivum L.). Genome. 2008;51(6):426-32.

52. Torada A, Koike M, Ogawa T, Takenouchi Y, Tadamura K, Wu J, et al. A causal gene for seed dormancy on Wheat chromosome 4A encodes a MAP kinase kinase. Curr Biol. 2016;26(6):782-7.

53. Zhang $Y, X i a X$, He Z. The seed dormancy allele TaSdr-Ala associated with pre-harvest sprouting tolerance is mainly present in Chinese wheat landraces. Theor Appl Genet. 2017;130(1):81-9.

54. Martynov S, Dobrotvorskaya T. Genealogical analysis of the northAmerican spring Wheat varieties with different resistance to preharvest sprouting. Proc Latvian Acad Sci Sec B Nat Exact Appl Sci. 2016;70(6):370-7.

55. DePauw RM, Clarke FR, Fofana B, Knox R, Humphreys G, Cloutier S. RL4137 contributes preharvest sprouting resistance to Canadian wheats. Euphytica. 2009;168(3):347-61.

56. Xiao-bo R, Xiu-jin L, Deng-cai L, Jia-li W, You-liang Z. Mapping QTLs for pre-harvest sprouting tolerance on chromosome 2D in a synthetic hexaploid wheat×common wheat cross. J Appl Genet. 2008:49(4):333-41.

57. Mori M, Uchino N, Chono M, Kato K, Miura H. Mapping QTLs for grain dormancy on wheat chromosome $3 \mathrm{~A}$ and the group 4 chromosomes, and their combined effect. Theor Appl Genet. 2005;110(7):1315-23.

58. Mohan A, Kulwal P, Singh R, Kumar V, Mir RR, Kumar J, et al. Genomewide QTL analysis for pre-harvest sprouting tolerance in bread wheat. Euphytica. 2009;168(3):319-29.

59. Cao L, Hayashi K, Tokui M, Mori M, Miura H, Onishi K. Detection of QTLs for traits associated with pre-harvest sprouting resistance in bread wheat (Triticum aestivum L.). Breed Sci. 2016;66(2):260-70.

60. Osa M, Kato K, Mori M, Shindo C, Torada A, Miura H. Mapping QTLs for seed dormancy and the $\mathrm{Vp} 1$ homologue on chromosome $3 \mathrm{~A}$ in wheat. Theor Appl Genet. 2003;106(8):1491-6.

61. Lohwasser U, Röder MS, Börner A. QTL mapping of the domestication traits pre-harvest sprouting and dormancy in wheat (Triticum aestivum L.). Euphytica. 2005;143(3):247-9.

62. Tuan PA, Kumar R, Rehal PK, Toora PK, Ayele BT. Molecular mechanisms underlying Abscisic acid/gibberellin balance in the control of seed dormancy and germination in cereals. Front Plant Sci. 2018;9:668.

63. Doebley JF, Gaut BS, Smith BD. The molecular genetics of crop domestication. Cell. 2006;127(7):1309-21

64. Wang M, Li W, Fang C, Xu F, Liu Y, Wang Z, et al. Parallel selection on a dormancy gene during domestication of crops from multiple families. Nat Genet. 2018;50(10):1435-41.

65. Lenser T, Theißen G. Molecular mechanisms involved in convergent crop domestication. Trends Plant Sci. 2013;18(12):704-14.

66. Meyer RS, Purugganan MD. Evolution of crop species: genetics of domestication and diversification. Nat Rev Genet. 2013;14(12):840-52.

67. Simpson GM. Seed dormancy in grasses. Cambridge: Cambridge University Press; 1990.

68. Brown PD, Randhawa HS, Mitchell Fetch J, Meiklejohn M, Fox SL, Humphreys DG, et al. AAC Tenacious red spring wheat. Can J Plant Sci. 2015;95:805-10.

69. Gondo T, Sato S, Okumura K, Tabata S, Akashi R, Isobe S. Quantitative trait locus analysis of multiple agronomic traits in the model legume Lotus japonicus. Genome. 2007;50(7):627-37.

70. Lin M, Zhang D, Liu S, Zhang G, Yu J, Fritz AK, et al. Genome-wide association analysis on pre-harvest sprouting resistance and grain color in U.S. winter wheat. BMC Genomics. 2016;17(1):794.

71. Fofana B, Humphreys DG, Rasul G, Cloutier S, Brûlé-Babel A, Woods S, et al. Mapping quantitative trait loci controlling pre-harvest sprouting resistance in a red $x$ white seeded spring wheat cross. Euphytica. 2009;165(3):509-21.

72. Munkvold JD, Tanaka J, Benscher D, Sorrells ME. Mapping quantitative trait loci for preharvest sprouting resistance in white wheat. Theor Appl Genet. 2009;119(7):1223-35.

73. Cabral AL, Jordan MC, McCartney CA, You FM, Humphreys DG, MaCLachlan $\mathrm{R}$, et al. Identification of candidate genes, regions and markers for pre-harvest sprouting resistance in wheat (Triticum aestivum L.). BMC Plant Biol. 2014;14:340.

74. Gasperini D, Greenland A, Hedden P, Dreos R, Harwood W, Griffiths S. Genetic and physiological analysis of Rht8 in bread wheat: an alternative source of semi-dwarfism with a reduced sensitivity to brassinosteroids. J Exp Bot. 2012;63(12):4419-36.

75. Dhariwal R, Henriquez MA, Hiebert C, McCartney CA, Randhawa HS. Mapping of major Fusarium head blight resistance from Canadian Wheat cv. AAC Tenacious. Int J Mol Sci. 2020;21(12):4497.

76. Randhawa HS, Graf RJ, Sadasivaiah RS. AAC Innova general purpose spring wheat. Can J Plant Sci. 2015;95(4):787-91.

77. Collard BCY, Jahufer MZZ, Brouwer JB, Pang ECK. An introduction to markers, quantitative trait loci (QTL) mapping and marker-assisted selection for crop improvement: the basic concepts. Euphytica. 2005;142(1):169-96.

78. Lander E, Kruglyak L. Genetic dissection of complex traits: guidelines for interpreting and reporting linkage results. Nat Genet. 1995;11(3):241-7.

79. Xi W, LiU C, Hou X, YU H. MOTHER OFFT AND TFL 1 regulates seed germination through a negative feedback loop modulating ABA signaling in Arabidopsis. Plant Cell. 2010;22(6):1733-48.

80. Chardon F, Damerval C. Phylogenomic analysis of the PEBP gene family in cereals. J Mol Evol. 2005;61(5):579-90.

81. Turck F, Fornara F, Coupland G. Regulation and identity of florigen: FLOWERING LOCUS T moves center stage. Annu Rev Plant Biol. 2008:59:573-94.

82. Carrillo-Barral N, Rodríguez-Gacio MDC, Matilla AJ. Delay of Germination-1 (DOG1): a key to understanding seed dormancy. Plants (Basel). 2020;9(4):480

83. Debeaujon I, Léon-Kloosterziel KM, Koornneef M. Influence of the testa on seed dormancy, germination, and longevity in Arabidopsis. Plant Physiol. 2000;122(2):403-14.

84. Wang Y, Wang XL, Meng JY, Zhang YJ, He ZH, Yang Y. Characterization of Tamyb10 allelic variants and development of STS marker for pre-harvest sprouting resistance in Chinese bread wheat. Mol Breed. 2016;36(11):148.

85. Himi E, Maekawa M, Miura H, Noda K. Development of PCR markers for Tamyb10 related to $R-1$, red grain color gene in wheat. Theor Appl Genet. 2011;122(8):1561-76.

86. Abe F, Haque E, Hisano H, Tanaka T, Kamiya Y, Mikami M, et al. Genomeedited triple-recessive mutation alters seed dormancy in Wheat. Cell Rep. 2019;28(5):1362-9 e1364.

87. Xiu-Jin L, Deng-Cai L, Zhi-Rong W. Inheritance in synthetic hexaploid wheat 'RSP' of sprouting tolerance derived from Aegilops tauschii Cosson. Euphytica. 1997;95(3):321-3.

88. Chono M, Matsunaka H, Seki M, Fujita M, Kiribuchi-Otobe C, Oda S, et al. Molecular and genealogical analysis of grain dormancy in Japanese wheat varieties, with specific focus on MOTHER OF FT AND TFL 1 on chromosome 3A. Breed Sci. 2015;65(1):103-9.

89. Whittal A, Kaviani M, Graf R, Humphreys G, Navabi A. Allelic variation of vernalization and photoperiod response genes in a diverse set of north American high latitude winter wheat genotypes. PLoS One. 2018;13(8):e0203068.

90. Trethowan R, Rajaram S, Ellison F. Pre-harvest sprouting tolerance in wheat in the field and under rain simulation. Aust J Agric Res. 1996;47(5):705-16.

91. Beales J, Turner A, Griffiths S, Snape JW, Laurie DA. A Pseudoresponse regulator is misexpressed in the photoperiod insensitive Ppd-D1 a mutant of wheat (Triticum aestivum L.). Theor Appl Genet. 2007; 115(5):721-33.

92. Hammer K. Das Domestikationssyndrom. Die Kulturpflanze 1984;32(1):11-34

93. Gepts P. Crop domestication as a long-term selection experiment. In: Plant Breeding Reviews; 2003. p. 1-44. 
94. Ross-Ibarra J, Morrell PL, Gaut BS. Plant domestication, a unique opportunity to identify the genetic basis of adaptation. Proc Natl Acad Sci. 2007; 104(suppl 1):8641.

95. Suenaga K, Nakajima K. Efficient production of haploid wheat (Triticum aestivum) through crosses between Japanese wheat and maize (Zea mays). Plant Cell Rep. 1989;8(5):263-6.

96. Randhawa HS, Graf RJ. AAC Awesome Special Purpose Spring Wheat. Can J Plant Sci. 2021. https://doi.org/10.1139/cjps-2021-0015.

97. Randhawa HS, Graf RJ, Sadasivaiah RS. AAC chiffon soft white spring wheat. Can J Plant Sci. 2014;94(7):1303-8.

98. Randhawa HS, Graf RJ, Sadasivaiah RS. AAC Indus soft white spring wheat. Can J Plant Sci. 2015;95(4):793-7.

99. Sadasivaiah RS, Perkovic SM, Pearson DC, Postman B, Beres BL. Registration of 'AC Andrew'Wheat. Crop Sci. 2004:44(2):696-7.

100. Sadasivaiah RS, Graf RJ, Randhawa HS, Beres BL, Perkovic SM, Virginillo M. Sadash soft white spring wheat. Can J Plant Sci. 2009;89(6):1099-106.

101. Brown PD, Randhawa HS, Fetch JM, Fox SL, Humphreys DG, Meiklejohn $\mathrm{M}$, et al. AAC foray red spring wheat. Can J Plant Sci. 2015;95(4):799-803.

102. Fox SL, Humphreys DG, Brown PD, McCallum BD, Fetch TG, Menzies JG, et al. Cardale hard red spring wheat. Can J Plant Sci. 2013:93(2):307-13.

103. Brown PD, Randhawa HS, Fetch JM, Meiklejohn M, Fox SL, Humphreys DG, et al. Conquer red spring wheat. Can J Plant Sci. 2017;97(1):147-52.

104. New cereal crop varieties registered in 2012 or supported for registration. https://www.producer.com/crops/new-cereal-crop-varieties-regis tered-in-2012-or-supported-for-registration/.

105. DePauw RM, Townley-Smith TF, Humphreys G, Knox RE, Clarke FR, Clarke JM. Lillian hard red spring wheat. Can J Plant Sci. 2005:85(2):397-401.

106. Thomas J, Fox S, McCallum B, Fetch T, Gilbert J, Menzies J, et al. Vesper hard red spring wheat. Can J Plant Sci. 2013;93(2):315-21.

107. Cuthbert RD, DePauw RM, Knox RE, Singh AK, McCaig TN, McCallum B, et al. AAC Brandon hard red spring wheat. Can J Plant Sci. 2016;97(2):393-401.

108. Cuthbert RD, DePauw RM, Knox RE, Singh AK, McCaig TN, McCallum $\mathrm{B}$, et al. AAC Penhold Canada prairie spring red wheat. Can J Plant Sci. 2017;98(1):207-14.

109. DePauw RM, Knox RE, McCaig TN, Clarke FR, Clarke JM. Carberry hard red spring wheat. Can J Plant Sci. 2011;91(3):529-34.

110. DePauw RM, Knox RE, Clarke FR, Clarke JM, McCaig TN. Stettler hard red spring wheat. Can J Plant Sci. 2009;89(5):945-51.

111. CDC Stanley [https://www.inspection.gc.ca/english/plaveg/pbrpov/ cropreport/whe/app00007708e.shtml].

112. Anderson JA, Sorrells ME, Tanksley SD. RFLP analysis of genomic regions associated with resistance to Preharvest sprouting in Wheat. Crop Sci. 1993;33(3):453-9 cropsci1993.0011183X003300030008x.

113. Paterson AH, Sorrells ME, Obendorf RL. Methods of evaluation for preharvest sprouting resistance in wheat breeding programs. Can J Plant Sci. 1989:69(3):681-9.

114. DePauw RM, Knox RE, Singh AK, Fox SL, Humphreys DG, Hucl P. Developing standardized methods for breeding preharvest sprouting resistant wheat, challenges and successes in Canadian wheat. Euphytica. 2012;188(1):7-14.

115. R Core Team: R. A language and environment for statistical computing. Vienna: R Foundation for Statistical Computing; 2013.

116. Wickham H, Averick M, Bryan J, Chang W, McGowan LDA, François R, et al. Welcome to the Tidyverse. J Open Source Softw. 2019;4(43):1686.

117. Kassambara A. ggpubr:'ggplot2' Based Publication Ready Plots. In., 0.1.1 edn; 2016.

118. Kassambara A. rstatix: Pipe-friendly framework for basic statistical tests; 2020.

119. Comparing Multiple Means In R [https://www.datanovia.com/en/lesso ns/mixed-anova-in-r/]

120. Mendiburu FD. agricolae: Statistical procedures for agricultural research R package version 1.2-3; 2015.

121. Kuznetsova A, Brockhoff PB, Christensen RHB. ImerTest package: tests in linear mixed effects models. J Stat Softw. 2017;1(13):2017.

122. Schloerke B, Crowley J, Cook D, Briatte F, Marbach M, Thoen E, et al. GGally: extension to 'ggplot2'. R package version 1.4.0; 2018.

123. Dhariwal $R$, Randhawa HS. Mapping quantitative trait loci in wheat: historic perspective, tools and methods for analysis. In: Bilichak A, Laurie JD, editors. Accelerated breeding for cereal crops. Springer Protocols
Handbooks. New York: Humana, New York; 2021. p. 31-75. https://doi. org/10.1007/978-1-0716-1526-3_2.

124. Zeng ZB. Theoretical basis for separation of multiple linked gene effects in mapping quantitative trait loci. Proc Natl Acad Sci. 1993:90(23):10972-6.

125. Zeng ZB. Precision mapping of quantitative trait loci. Genetics. 1994:136(4):1457-68

126. Yang J, Hu C, Hu H, Yu R, Xia Z, Ye X, et al. QTLNetwork: mapping and visualizing genetic architecture of complex traits in experimental populations. Bioinformatics. 2008;24(5):721-3.

127. Dhariwal R, Fedak G, Dion Y, Pozniak C, Laroche A, Eudes F, et al. High density single nucleotide polymorphism (SNP) mapping and quantitative trait loci (QTL) analysis in a Biparental spring Triticale population localized major and minor effect Fusarium head blight resistance and associated traits QTL. Genes. 2018;9(1):19.

128. Hu Y, Yan C. OmicCircos: High-quality circular visualization of omics data. R package version 1.16.0; 2015

129. Altschul SF, Gish W, Miller W, Myers EW, Lipman DJ. Basic local alignment search tool. J Mol Biol. 1990;215(3):403-10.

130. Dobrotvorskaya T, Dobrotvorskiy D, Martynov S. GRIS: genetic resources information system for Wheat and Triticale. St. Petersburg: N.I.Vavilov research Institute of Plant Industry (VIR), St. Petersburg, Russia and international maize and Wheat improvement center (CIMMYT), Ankara, Turkey.

131. Fradgley N: NIAB Wheat pedigree. Helium categorical info format (updated 12.09.19).Txt. Figshare. Dataset; 2019.

132. Fradgley N, Gardner KA, Cockram J, Elderfield J, Hickey JM, Howell P, et al. A large-scale pedigree resource of wheat reveals evidence for adaptation and selection by breeders. PLoS Biol. 2019;17(2):e3000071.

133. Osanai S-I, Amano Y, Mares D. Development of highly sprouting tolerant wheat germplasm with reduced germination at low temperature. Euphytica. 2005;143(3):301-7.

134. Garlinge J. 2005 Crop variety sowing guide for Western Australia, vol. 2005. Western Australia: Food DoAa, vol. bulletin 4655. p. 1-205.

135. Shaw PD, Graham M, Kennedy J, Milne I, Marshall DF. Helium: visualization of large scale plant pedigrees. BMC Bioinformatics. 2014;15(1):259.

\section{Publisher's Note}

Springer Nature remains neutral with regard to jurisdictional claims in published maps and institutional affiliations.

Ready to submit your research? Choose BMC and benefit from

- fast, convenient online submission

- thorough peer review by experienced researchers in your field

- rapid publication on acceptance

- support for research data, including large and complex data types

- gold Open Access which fosters wider collaboration and increased citations

- maximum visibility for your research: over 100M website views per year

At BMC, research is always in progress.

Learn more biomedcentral.com/submissions 